\title{
Class Inequality in Parental Childcare Time: Evidence from Synthetic Couples in the ATUS
}

\author{
Joe LaBriola \\ UC Berkeley \\ Department of Sociology \\ Daniel Schneider \\ Harvard Kennedy School \\ Harvard University*
}

November 11, 2020

Conditionally accepted at Social Forces.

\begin{abstract}
The time that parents spend teaching and playing with their young children has important consequences for later life achievement and attainment. Previous research suggests that there are significant class inequalities in how much time parents devote to this kind of developmental childcare in the United States. Yet, due in part to data limitations, prior research has not accounted for how class inequalities in family structure, assortative mating, and specialization between partners may exacerbate or ameliorate these gaps. We match parental respondents within the American Time Use Survey to generate synthetic parental dyads, which we use to estimate, in turn, the contributions of family structure, assortative mating, and specialization to class gaps in parental time spent in developmental care of children aged 0-6. We find some evidence that accounting for class differences in family structure widens income gaps in total parental time in developmental childcare of young children. Further, we show that assortative mating of parents further contributes to educational gaps in developmental childcare, while specialization between partners does not offset these wider class divides. While the net effect of these three processes on income-based gaps in childcare time is more modest, accounting for these three processes more than doubles education-based gaps in total parental developmental childcare as compared to maternal time alone. Our findings from this novel empirical approach provide a more holistic view of the extent and sources of inequality in parental time investments in young children's cognitive and social development.
\end{abstract}

* Joe LaBriola (Corresponding author): UC Berkeley, Department of Sociology, 366 Barrows Hall, Berkeley, CA 94720; joelabriola@berkeley.edu. We thank Dierdre Bloome, Paula England, Sarah Flood, Pilar Gonalons-Pons, Pat Hastings, Peter Hepburn, Ian Lundberg, Christine Schwartz, Wendy Sigle, Herb Smith, and seven anonymous reviewers at Social Forces for helpful comments. A draft of this paper was presented at the 2018 Meetings of the Population Association of America. The authors thank the Russell Sage Foundation (Grant \#83-17-15), the National Science Foundation Graduate Research Fellowship Program (Grant \#1752814), and the National Institute of Child Health and Human Development (Grant \#T32-HD007275) for research support. 
Early childhood is likely the most consequential period for the development of socio-emotional and cognitive skills, in large part because early skill development lays a necessary foundation for future skill acquisition (Heckman 2006). Because children are most receptive to environmental influences during early childhood, investments in children during this period play a crucial role in child development. While it has proven very difficult to establish causal effects of parental time investment in childcare time on later life outcomes (e.g. Milkie et al. 2015), there is a large body of research that shows consistent positive associations. In particular, for young children, parental childcare time in developmentally enriching activities such as playing or talking with children, reading with children, or helping children with homework (hereafter "developmental childcare time") is positively associated with cognitive outcomes (Fiorini and Keane 2014; Hsin and Felfe 2014; Del Bono et al. 2016; Cano et al. 2019; Li and Hamlin 2019), child behavior (Hsin and Felfe 2014; Gialamas et al. 2019), and academic performance (Villena-Roldán and Ríos-Aguilar 2011; Price and Kalil 2018). However, this developmental childcare time is sharply stratified by parental socioeconomic class in the United States (e.g., Kalil et al. 2012; Hsin and Felfe 2014; Altintas 2016; Vinopal and Gershenson 2017). Socioeconomic divides in developmental childcare time for young children are thus one mechanism among several (including, e.g., socioeconomic divides in exposure to environmental stressors; see McEwen and McEwen 2017) that may lead to inequality in child well-being and later life attainment.

Scholarship on parental developmental childcare time generally examines gaps in maternal or paternal childcare time, not in combined parental childcare time (though see Sandberg and Hofferth, 2001; Folbre et al. 2005; and Phillips 2011 for important exceptions using the 1997 PSID CDS). Yet, family structure is sharply stratified by income and education in the United States-children born to college educated and higher-earning parents are much more likely to grow up in two-parent households than less advantaged children (McLanahan 2004). Class disparities in family structure are likely to lead to wider class gaps in total parental developmental childcare time than in maternal or paternal care alone, simply through the effect of the presence of an additional household parent. Further, the United States has high levels of marital homogamy with the respect to education (Mare 2016) and earnings (Schwartz 2010), both of which could have further effects on inequality in the family contexts of children (Schwartz 2013). The result then is that existing research that examines only one parents' developmental childcare time may seriously underestimate differences in 
total developmental childcare time by education and income. It is also possible that the effects of family structure and assortative mating on class gaps in total developmental childcare received by household children are partially reduced to the extent that parents specialize in either paid work or childcare (Becker 1981).

Previous research has not directly estimated the separate effects of the above three mechanismsclass gaps in family structure, class-based assortative mating, and specialization between partnerson class gaps in parental developmental childcare time. The investigation of these effects on total parental developmental childcare time has been hampered by the fact that the highest-quality data on time use in the United States, the American Time Use Survey (ATUS), only contains a time diary for one adult respondent per household. While the Child Development Supplement of the Panel Study of Income Dynamics (PSID-CDS) contains child-centered time diaries, researchers have not used this data source to examine whether or how these family processes contribute to class gaps in childcare time. Our research fills this gap in the literature by successively estimating the contributions of family structure, assortative mating, and specialization between partners to education- and income-based gaps in total parental developmental childcare time received by young children (defined here as children aged 0-6). Our general method is to create synthetic parent dyads by matching ATUS respondents to alters in the ATUS data, in order to estimate the developmental childcare time provided by ATUS respondents' coresident partners (or non-coresident co-parent).

We find that accounting for family structure significantly widens gaps in parental developmental childcare time by household income, but not by maternal education. Educational gaps in developmental childcare are, however, significantly widened after further accounting for assortative mating, though assortative mating does not drive wider income-based gaps. Accounting for these two demographic processes then produces wider class-gaps, by both education and income, in parental developmental childcare time than we observe when considering maternal time alone. Finally, specialization does not significantly affect class gaps in parental developmental childcare. Accounting for all three processes - family structure, assortative mating, and specialization - serves to widen maternal education-based gaps in this parental childcare time by over 27 minutes per day, or over $150 \%$ the size of education-based gaps in maternal childcare time alone. We also estimate that these processes widen income-based gaps in developmental childcare time by over $40 \%$ relative to income-based gaps in maternal childcare time. Given the importance of parental developmental 
childcare time with young children for the future well-being of children, our results suggest that total parental developmental childcare time is a mechanism through which assortative mating and class gaps in family structure translate into inequality in child outcomes.

\section{Background}

\section{Class Gaps in Parental Childcare Time}

Parental socioeconomic class strongly influences parental childcare time, with parents in higherincome households (Ramey and Ramey 2010; Schneider et al. 2018) and with higher levels of education (Ramey and Ramey 2010; Guryan et al. 2008; Kalil et al. 2012) performing more childcare. While income and education are strongly correlated, scholars of the family have placed importance on both dimensions of socioeconomic class as distinct drivers of unequal parental investment in children. Research on parental behaviors associated with the concerted cultivation of children has shown that parental education is the greatest predictor of these behaviors (Cheadle and Amato 2011:697-8), while income, net of education, also appears to allow parents to increase their investments in their children (Kornrich and Furstenberg 2013; Schneider et al. 2018).

Further, these class gaps in maternal and paternal investments of time by class appear to have widened in recent years in the United States. Charting childcare time in the United States, Ramey and Ramey (2010) find that the gap between college-educated and less-educated mothers widened substantially after the mid-1990s. Schneider et al. (2018) also find evidence in the United States of widening divides between households in the top income decile and lower-income households in terms of childcare time, with fathers of high-income households in particular appearing to increase their childcare time relative to other fathers since $2000 .{ }^{1}$ Though much research on parental childcare time focuses on a broader conceptualization of childcare than play and/or educational activities, and on childcare performed for all and not just young children, similar socioeconomic gaps in developmental childcare time can be seen among households with young children in the United States (Kalil et al. 2012; Hsin and Felfe 2014; Altintas 2016; Vinpal and Gershenson 2017).

However, this existing research has been constrained both empirically and theoretically. In terms of empirics, the extant literature generally focuses on maternal or paternal childcare time

\footnotetext{
${ }^{1}$ Research from other countries suggests that the widening of class gaps in parental childcare time may be limited to the case of the United States. Class gaps in childcare time did not widen in Spain over the Great Recession (Cano 2019), and actually appear to have recently narrowed in Australia (Craig, Powell, and Smyth 2014).
} 
separately and thus does not account for the total childcare time that children receive from both mothers and fathers. In terms of theory, while demographic perspectives have emphasized the role of class divergence in the familial settings in which childcare takes place, existing work has not attempted to account for how these transformations may have affected class gaps in parental childcare. Below, we discuss two crucial theoretical perspectives that will extend our understanding of the differentiation of childcare time by class - family structure and assortative mating.

\section{Class Gaps in Family Structure}

Theories of the second demographic transition (Lesthaeghe 2010) and of diverging destines (McLanahan 2004) would suggest that these well-documented class-gaps in maternal childcare time might be exacerbated by class gaps in family structure. Children whose parents are highly educated (McLanahan 2004) or higher income (e.g., Martin 2006; Census Bureau 2017) are also more likely to grow up in a two-parent household, due to educational and income divides in non-marital fertility, marriage, and divorce (e.g., Martin 2006; Gibson-Davis and Rackin 2014). For instance, in 2015, $54 \%$ of householders with less than a high school degree who were raising children were married as compared with $81 \%$ of householders with at least a bachelor's degree (Authors' calculation from Census Table F2 2015).

Class gaps in family structure could affect class gaps in total parental childcare time through an intensive margin (i.e., married parents performing more childcare than unmarried parents) or through an extensive margin (i.e., the number of parents who are present and performing care). While there is some evidence that individual mothers who are married spend more time in childcare than those who are unmarried (Bianchi et al. 2006; Kendig and Bianchi 2008), the differences are not large (Pepin et al. 2018; Bianchi 2011). Further, research suggests that these small differences can be accounted for by differences in household economics (Kendig and Bianchi 2008; Sayer et al. 2004) or by selection into marriage (Kalenkoski et al. 2007). However, it is likely that the effect on the extensive margin could have large effects on the total amount of parental childcare time received by the children of higher- and lower-SES parents. For example, non-coresidential fathers spend very little time performing childcare (Carlson and Berger 2013), while married fathers spent more than 7 hours per week caring for children (Parker and Wang 2013). Indeed, Kalil et al. (2013) find large and significant differences in total caregiving time received by children in married parent 
households as compared to those growing up with a single mother.

Yet, research on parental childcare time has not directly investigated how class gaps in family structure are implicated in class gaps in developmental childcare time. An important exception is the work of Sandberg and Hofferth (2001:429), who examine the 1997 PSID-CDS and find that children whose mothers had a college degree spent three more hours each week in the care of either parent than children whose mothers did not have a college degree. They further report that this education gap was one hour wider among all family structures than among two-parent families, which suggests that a meaningful portion of the education gaps in parental time are due to education gaps in family structure. However, this research relies on data that is currently over two decades old, measures a different construct of childcare time (total time children were co-present with parents), and only reports a difference in means without controlling for other factors known to affect childcare time (e.g., family income, number of household children, and age of the youngest household child).

\section{Assortative Mating}

Beyond family structure, demographic theories of mate selection and homogamy raise the question of if class gaps in parental developmental childcare time might be driven in part by parents matching based on educational attainment or income, both of which are predictors of parental childcare time. Research finds that assortative mating has increased over the past several decades along lines of education (Mare 2016; Shen 2019). Similarly, economic homogamy has increased in the United States (Schwartz 2010), driven primarily by a rise in dual-earner households rather than increased matching based on earnings potential (Gonalons-Pons and Schwartz 2017). These increased class divides in the educational composition and earnings of married couples are likely to lead to increased class gaps in total parental developmental childcare time simply through additive effects, since highly-educated and high-earning parents perform more developmental childcare.

Further, the joint determination of childcare time between partners may also be affected by the degree of assortative mating between partners if homogamous couples have more similar timeuse preferences, and if these preferences are reinforcing such that there are multiplicative effects on parental childcare time. However, the evidence for this mechanism is not robust. Bonke and EspingAndersen (2011) claim to find evidence in Denmark of a positive effect of educational homogamy on shared childcare time for highly-educated parents, which they attribute to jointly-determined 
time-use preferences among highly-educated parents; but, as noted by Macdonald (2011:283), this finding may be a consequence of a misspecified regression model. Further, England and Srivastava (2013:982) find no consistent evidence in the ATUS for the effects of educational homogamy on individual parents' time spent in childcare.

Previous research has not isolated the contribution of the effects of assortative mating towards class gaps in parental childcare time, though some scholars have made indirect estimates. Altintas (2016) creates estimates of gaps in total parental childcare time by parental education, using the individual time diary data in the 1966-2012 American Heritage Time Use Survey. When taking into account education-based gaps in father absence and assuming full educational homogamy among married partners, Altintas (2016) finds much wider education-based gaps in total parental childcare time than in either maternal or paternal childcare time. Though useful, this analysis does not disentangle the effects of assortative mating on class gaps in total parental childcare time from the effects of class gaps in family structure. Further, the assumption of full educational homogamy is probably too strong, given that just over half of marriages are between educationally homogamous individuals (Schwartz and Mare 2005).

\section{Specialization Between Partners}

Finally, economic theories of the household (Becker 1981) suggest that total parental childcare time could be affected by within-household specialization between partners, whereby one partner spends relatively more time in paid work while the other spends relatively more time in unpaid developmental childcare. Such specialization could come about by each partner spending more time in activities in which they have a comparative advantage (Becker 1981), or by higher-earning partners using their bargaining power to spend less time in household production (Gupta and Stratton 2008). This perspective proceeds from the general assumption in theory and research on specialization that childcare is fundamentally similar to other forms of unpaid labor, such as routine housework. But, there is also good reason to suspect that the household dynamics shaping time spent in these two forms of unpaid labor may in fact operate very differently, with parents of all social classes viewing intensive parenting as an investment good rather than a routine and unpleasant task (Ishizuka 2019).

Studies find mixed evidence of specialization between partners in childcare resulting from differ- 
ences in earnings or time spent in paid work. Examining married mothers and fathers in the 2003-07 ATUS, Raley et al. (2012) show that mothers' employment and time spent in paid work are associated with fathers performing more childcare, both as measured in absolute terms as well as a ratio to the time mothers spend performing childcare. However, Connelly and Kimmel (2009) find no effect of the relative wage between spouses on either spouse's allocation of time towards childcare, though in later work (Connelly and Kimmel 2010), they find that husbands' weekly employment time is positively related to wives' time in caregiving.

Any specialization between partners could reduce income-based gaps in total parental childcare time if, for example, a sufficiently large portion of higher-income households are characterized by high-earning men who provide relatively little childcare. On the other hand, if higher-income households are more likely to be characterized by dual earners with similar marginal productivities in work than are lower-income households, accounting for specialization between partners could actually reveal wider income-based gaps in parental childcare time. As with family structure and assortative mating, research has yet to examine the effect of specialization between partners in paid work and childcare on class gaps in childcare time.

\section{Our Contribution}

Previous literature that has examined class gaps in parental childcare time has generally relied on the large-scale and high-quality time diary data available in the ATUS (e.g., Bianchi et al. 2004; Guryan et al. 2008; Ramey and Ramey 2010; Kalil et al. 2012; Altintas 2016). However, the estimation of total parental childcare time using the ATUS-and how this time is shaped by family structure, assortative mating, and specialization between partners-is made more difficult by the fact that the ATUS only collects a time diary from one respondent per household. Though some estimates of class gaps in total parental childcare time have relied on the 1997 PSID-CDS (Folbre et al. 2005; Phillips 2011), these studies rely on data that is now over twenty years old, and do not

investigate how class gaps in family structure, class-based assortative mating, and specialization between partners may affect class gaps in total parental childcare time.

We advance the literature on inequalities in total parental childcare time by making novel use of the ATUS. We focus on parental developmental childcare time-including time spent in play and in educational activities such as reading and homework help-for children aged 0-6. By focusing on 
parental developmental childcare for younger children, we focus on the type of care that studies taking both panel (Fiorini and Keane 2014, Del Bono et al. 2016, Cano et al. 2019, Gialamas et al. 2019; Li and Hamlin 2019) and quasi-experimental approaches (Villena-Roldán and Ríos-Aguilar 2011; Hsin and Felfe 2014; Price and Kalil 2018) have shown is most beneficial for child outcomes, performed at an age where these investments are most consequential (Heckman 2006).

Our innovation is to exploit the detailed data in the ATUS on both the characteristics of diarists and the characteristics of their spouses or coresident partners (hereafter "partners") to simulate couples and so calculate total parental developmental childcare time. In brief, we match diarists (described by a vector of characteristics $R_{i}$ ) who have partners (described by vector $P_{i}$ ) and who jointly share a vector of household-level characteristics $\left(H_{i}\right)$ with alters $R_{j}$ who have similar partner characteristics as $P_{i}$, who are partnered with individuals $P_{j}$ with the similar characteristics as $R_{i}$, and also match on household-level characteristics. We then impute parental developmental childcare time by matched alters $R_{j}$ as estimates of the time in childcare by $P_{i}$, which allows us to estimate total parental developmental childcare time by $R_{i}$ and $P_{i}$. We perform a similar matching algorithm to match time diaries of single parents with time diaries of non-coresident parents of the opposite sex. These matches allow us to bound estimates of total parental time spent in developmental childcare, using one measure that simply sums up the developmental childcare performed by the respondent and their alter, and another that adjusts for developmental childcare time that is performed in the presence of one's partner.

We use this matching technique to create three sets of synthetic parental dyads, in order to sequentially estimate the effects of accounting for family structure, assortative mating, and specialization within partnerships on class gaps in total parental developmental childcare time. We create the first set of synthetic parental dyads by matching respondents to alters based on characteristics related to family structure, the second set of dyads by matching respondents to alters based on characteristics related to family structure and assortative mating, and the third set of dyads by matching respondents to alters based on characteristics related to family structure, assortative mating, and specialization between partners. By comparing class gaps in maternal developmental childcare time to the estimated class gaps in total parental developmental childcare time in the first set of synthetic parental dyads, we are able to estimate the contribution of class gaps in family structure to class gaps in total parental developmental childcare time. Similarly, we estimate the 
effect of class-based assortative mating on class gaps in total parental developmental childcare time by comparing the class gaps in total parental developmental childcare time we observe in the second set of dyads to those in the first set of dyads. Finally, by comparing class gaps in total parental developmental childcare time between the second and third set of dyads, we estimate the effect of specialization between partners on class gaps in total parental developmental childcare time.

\section{Data and Methods}

\section{American Time Use Survey}

The ATUS, which has been administered since 2003, is a nationally-representative time-diary survey designed to provide estimates of time use in the United States. The ATUS selects a sample of the respondents in the Current Population Survey (CPS) who completed their last CPS survey 2-5 months prior and assigns each sampled respondent a specific day to fill out a detailed 24-hour time diary. Importantly, the ATUS also contains demographic and labor force information for respondents and their partners (much of it collected from respondents' final CPS survey), as well as information on the characteristics of other household members and their relationships to the respondent.

Taken together, this information allows us to identify a sample of ATUS respondents aged 18-65 who are living with one or more of their their own children (defined by the ATUS as biological, step-, or adopted children) aged 0-6, or who have an own child aged 0-6 with whom they do not live. We further limit our sample to those who were not flagged as filling out a low-quality time diary, did not fill out their diary on a holiday, and did not have missing values for household income. We also drop respondents who filled out their final CPS survey before October 2003, as a result of a change in how the CPS coded family income in October 2003 that more accurately allows us to capture high-income households. ${ }^{2}$ The resulting sample consists of 16,716 mothers and 11,768 fathers surveyed between the years of 2003 and 2018. We access ATUS data through the American Time Use Survey Extract Builder (ATUS-X; Hofferth et al. 2020).

\section{Parental Childcare Time}

While we have detailed information on the characteristics of all household members, ATUS only includes time diaries for the respondent. We measure parental developmental childcare time as

\footnotetext{
${ }^{2}$ Here, we drop approximately $12 \%$ of observations. As described in Appendix A, we re-weight our sample at this step to ensure that the resulting sample is demographically similar to the original sample.
} 
the number of minutes in a diary day that a respondent reports playing with, reading to or with, talking with or listening to, and helping or teaching their own household children aged 0-6 (ATUS activity codes 030102-030107, 030201, and 030203). This definition of developmental childcare time incorporates the two types of direct engagement with children-play, and engagement in educational activities-which extant research highlights as most beneficial for the cognitive and non-cognitive outcomes for young children. Conversely, our measure does not capture time spent performing basic physical care of children, or childcare time where the parent is not directly engaging with children (including time spent managing children's activities or in travel related to caring for children), both of which are less strongly associated with child outcomes.

For all parents in our sample living with their own children, we calculate this measure of childcare as that done in the presence of their own household child aged 0-6. In order to estimate total parental time received by children in single-parent households, we calculate a similar measure of developmental childcare time (ATUS activity codes 040102-040107, 040201, and 040203) performed by parents who have children with whom they do not live. We use the hierarchical time-diary extracts available on ATUS-X to identify developmental childcare time that is performed with own non-household children aged 0-6. Tables 1 and 2 show that parental respondents in the ATUS with more education and higher family incomes spend more time in developmental childcare for their children aged 0-6, and are more likely to live with a coresident partner. Further, we find that non-coresidential fathers contribute relatively little developmental childcare time to their noncoresidential children aged 0-6.

\section{ATUS Variables Used in Matching Procedures}

In all matching procedures, we account for whether the time diary is filled out on a weekend or weekday, since there are significant differences in parental childcare time between weekends and weekdays (Hill et al. 2018). Below, we describe in turn the variables that we use to account for matching by family structure, assortative mating, and specialization.

\section{Family Structure}

We account for the contribution of class differences in family structure by first matching parental respondents by coresident status: parental respondents with coresident partners of a given sex are 
matched with alters of that sex who also have coresident partners ${ }^{3}$ while parental respondents without coresident partners are matched with opposite-sex respondents who have a child aged 0-6 with whom they do not live. This matching imputes childcare time for all coresident partners, whether they are a biological, step-, or adoptive parent of household children. For partnered respondents, we also match based on the number of children aged 0-6 living in their household and the age of the youngest child in their household. We perform this matching based on family structure in generating each of our three sets of synthetic parental dyads.

\section{Assortative Mating}

In our second and third sets of synthetic parental dyads, we augment the matching based on family structure to account for the additional contribution of assortative mating to class differences in parenting time. We do so by matching based on age, race (coded as White/ other), and education. For parental respondents with coresident partners, this matching occurs for both the respondent and their partner: the respondent's age, race, and education are matched with the age, race, and education of the alter's partner, while the respondent's partner's age, race, and education is matched with that of the alter. For respondents without coresident partners, we match their age, race, and education to that of other respondents who have children aged 0-6 with whom they do not live. Additionally, for respondents with coresident partners, we match based on household income. ${ }^{4}$

\section{Specialization}

Finally, in our third set of synthetic parental dyads, we additionally account for specialization between partners by also matching on usual hours worked per week of each partner and logged relative wages between partners. We do not expect within-household specialization to affect the total parental childcare time received by children who live with a parent not residing with a coresident partner. As such, we match these parents with with non-coresident co-parents using the same variables as when matching based on assortative mating.

\footnotetext{
${ }^{3}$ This allows for the possibility of matching between respondents in opposite-sex relationships and alters in samesex relationships, or vice versa. We thus carry the assumption that childcare time is more significantly determined by one's own sex and not by that of one's partner.

${ }^{4}$ We code household income as the midpoint of the reported income category in the ATUS, with those in the income category of over $\$ 150,000 /$ year coded as a household income of $\$ 175,000$. We then adjust these values for inflation. We test the robustness of our results to adjusting household income for household size using two different equivalence scales-one that divides household income by the square root of the number of people in the household, and another that gives children less weight to account for their lower consumption of resources. Our results are similar when using these adjusted measures of household income.
} 
Matching on usual hours worked per week allows us to test whether time spent in work crowds

out time for childcare (e.g. Bianchi et al. 2006, though see Hsin and Felfe 2014). Further, the amount of time that both partners spend in work is likely to partially reflect any jointly-made decisions about how to allocate childcare time within the household. We match on relative wages between partners because theories of specialization between partners and of bargaining power in relationships both predict that partners who earn relatively more money in paid work will spend less time in unpaid childcare. It follows that the degree of specialization within a household will be a function of the relative wages between partners, as measured by the wage of an individual divided by the wage of their partner (Pollak 2005; Connelly and Kimmel 2009). See Appendix A for a detailed description of how we estimate relative wages between partners.

\section{Matching Procedure}

In creating each of our three sets of synthetic parental dyads (one which matches on family structure, a second which additionally matches on assortative mating, and a third which additionally matches on specialization between partners), we match respondents to alters using two steps.

First, we use coarsened exact matching (Iacus et al. 2012) in order to place respondents in subsets with alters who have similar values as the respondents on all matching variables. We begin by coarsening all $n$ matching variables $\left(X_{1}, \ldots, X_{n}\right)$ into categorical variables $\left(X_{1}^{C}, \ldots, X_{n}^{C}\right)$, so that respondents with similar values for a given matching variable are grouped into the same category in the coarsened variable. Then, each respondent is placed into a subset of all respondents with alters who share the same values of all $n$ coarsened variables; that is, for any $i$ and $j$ in the same matched subset, $\left(X_{1} i^{C}, \ldots, X_{n} i^{C}\right)=\left(X_{1} j^{C}, \ldots, X_{n} j^{C}\right)$.

The main benefit of this procedure is to ensure that respondents are not matched to alters who do not share similar values on covariates that are important for explaining an outcome of interest, which may occur in matching procedures (like the propensity score or the Mahalanobis distance) in which the covariates used for matching are projected from their original n-dimensional space to a unidimensional space (Iacus et al. 2012). Importantly for this project, using coarsened exact matching allows us to ensure that, when we account for assortative mating in matching, each match aligns with the attainment of educational credentials and the categories of household income that we use to estimate class gaps in childcare time. 
The choice of what cut-points are used for coarsening each variable - and how many cut-points are used - affects the types of matches that are made in coarsened exact matching. Some variables are categorical and do not need cut-points; for some continuous variables, cut-points can be chosen on substantive criteria (e.g., cutting years of education to split respondents into levels of educational attainment). For other continuous variables, there is a trade-off between the closeness of the match (which rises with more cut-points) and the percentage of respondents that are matched (which declines with more cut-points). In general, we used more cut-points for variables that were more strongly correlated with childcare time, and selected cut-points so that there were roughly an equal number of respondents in the 'bins' defined by the cut-points. Appendix Table 1 describes which cut-points were used for all variables.

We also test the robustness of the coarsening procedure by either a) making small changes to the cut-points used for a variable or b) adding an additional cut-point for a variable. We perform each of these robustness checks for five variables-age of youngest child, number of household children under the age of 7 , respondent age, usual weekly hours worked, and relative wages between partnersfor ten robustness checks in all. Our findings are robust to these permutations of the coarsening procedure (results available upon request).

All respondents had at least one match after coarsened exact matching on family structure. Just under $10 \%$ of respondents were not matched after additionally using coarsened exact matching on assortative mating, and an additional $23 \%$ of the original sample of respondents were not matched after additionally using coarsened exact matching on specialization. In our analyses, we drop these respondents and reweight the samples of respondents who have matches after accounting for assortative mating and/or specialization to match the demographic characteristics of the full sample of mothers living with at least one own child aged 0-6. Our results are substantively similar without reweighting, or if we only focus on the subsample that matches on specialization between partners and reweight this subsample to match the sample of all respondents. See Appendix B for more detail about this reweighting.

Second, to find more precise matches within the subsets defined by coarsened matching, we calculate the Mahalanobis (1936) distance based on the uncoarsened matching variables between respondents in the same subset. The Mahalanobis distance between respondents $i$ and $j$ is as follows: 


$$
d_{M}(i, j)=\sqrt{\left(\left(X_{1} i, \ldots, X_{n} i\right)-\left(X_{1} j, \ldots, X_{n} j\right)\right)^{T} \Sigma^{-1}\left(\left(X_{1} i, \ldots, X_{n} i\right)-\left(X_{1} j, \ldots, X_{n} j\right)\right)} .
$$

where $\Sigma$ is the covariance matrix of $Y$ in the entire group of potential matches. The inclusion of the covariance matrix in the Mahalanobis distance accounts for variables having different variances as well as for the covariance between variables. We match each respondent to the alter in their subset who is closest in terms of Mahalanobis distance. If there are multiple such alters, we randomly select one alter as the match. As described in more detail in Appendix C, when predicting class gaps in total parental childcare time, we account for the variance in total parental childcare time that stems from this random selection using multiple imputation.

After matching respondents to an alter, we then calculate the total parental developmental childcare time associated with each respondent, $C^{T}$, as the sum of their own developmental childcare time, $C^{r}$, and that of their matched alter, $C^{p}$. For parents with coresident partners, $C^{p}$ represents developmental childcare time of their alter (a parent with coresident children) performed for their household children aged 0-6; for parents without coresident partners, $C^{p}$ represents developmental childcare time of their alter (a parent with non-household children) performed for non-household children, while in the presence of their own non-household child aged 0-6.

\section{Adjusting Childcare Time for Parental Copresence}

Our main measure of total parental developmental childcare time sums up developmental childcare time of a respondent and their matched alter, and does not adjust for developmental childcare time that partners may perform together. While the ATUS asks respondents who is present during all activities recorded in time diaries, it does not record what activities these individuals are engaging in themselves-so, it is not possible to tell whether a partner who is present when a respondent is spending time in developmental childcare for their young child is engaging in developmental childcare themselves. To the extent that partners do perform developmental childcare together, simply summing up developmental childcare time of a respondent and their matched alter will overestimate the childcare time actually received by young household children. However, there is reason to believe that shared childcare may have additional developmental benefits for children: to the extent that coparenting time is spent positively, it may lead to better emotional adjustment for children (McHale and Rasmussen 1998) and stronger relationships between family members (Cox 
and Paley 2003), while also providing a positive model for children for how adults should interact (Bandura 1977). Further, time spent doing childcare in the presence of a partner is arguably often preferable for parents because they can share some of the work of childcare with their partner (Folbre et al. 2005). If joint childcare relieves parents of some of the stressors of solo childcare, then, from the perspective of the child, their time spent receiving childcare may be more enjoyable and developmentally enriching. Still, in Appendix D, we additionally calculate measures of total developmental childcare time that accounts for childcare performed in the presence of one's partner, and use these adjusted measures to estimate the effects of family structure, assortative mating, and specialization between partners on class gaps in total developmental childcare time.

\section{Analysis}

We first compare class gaps in maternal childcare time among mothers who live with their children to class gaps in our estimates of total parental developmental childcare time from our three sets of synthetic parental dyads: one in which we match based on family structure, a second in which we match based on family structure and assortative mating, and a third in which we match based on family structure, assortative mating, and specialization between partners. Here, we measure gaps in mean developmental childcare time by levels of maternal education, which has been the standard in the literature, and thus focus on the subsample of respondents who are mothers (though results are substantively similar when considering all respondents). As such, our findings generalize to the population of households where mothers live with at least one own child aged 0-6. We report both unadjusted and adjusted (equation 3) measures of total parental developmental childcare time. All estimates account for the recommended survey weighting provided by ATUS and use replicate weights provided by ATUS-X.

Next, again focusing on maternal respondents who live with their children, we more directly test for the effects of family structure, assortative mating, and specialization between partners on class gaps in total childcare received by children using ordinary least squares regressions. Formally, for a given measure of total developmental childcare $C_{i}^{T}$, we estimate:

$$
C_{i}^{T}=\beta_{0}+\beta_{1} \text { MatEd }_{i}+\beta_{2} \text { FamInc }_{i}+\beta_{3} Z_{i}+\epsilon_{i} .
$$

Here, we operationalize maternal education as a three-category variable (a high school degree 
or less, some college but no Bachelor's degree, and a Bachelor's degree or higher) and family income as a three-category variable (0-25th income percentiles, 25th-75th percentiles, and 75th-100th percentiles). We use the reference groups of some college but no Bachelor's degree (for maternal education) and 25th-75th income percentiles (for family income). We include as control variables the age of the youngest household child, the number of household children aged 0-6, maternal age, whether the mother is White, whether the mother is employed, and whether the time diary was filled out on a weekend. ${ }^{5}$

To test the successive effects of family structure, assortative mating, and specialization on class gaps in total developmental childcare time, we want to test whether there is a significant difference between regression coefficients $\beta_{1}$ and $\beta_{2}$ when using different estimates of developmental childcare time as dependent variables. We do so using a flexible method (Clogg et al. 1995) that does not assume equality of error variances between models. Given coefficients $\beta_{i}^{T, 1}$ and $\beta_{i}^{T, 2}$ estimated from regressions on two measures of developmental childcare time $C^{T, 1}$ and $C^{T, 2}$, respectively, we calculate a Z-test for the difference between these coefficients as follows:

$$
Z=\frac{\beta_{i}^{T, 1}-\beta_{i}^{T, 2}}{\sqrt{\left(S E \beta_{i}^{T, 1}\right)^{2}+\left(S E \beta_{i}^{T, 2}\right)^{2}}} .
$$

We estimate Z-tests between regression coefficients to make three comparisons of measures of developmental childcare time: 1) between maternal developmental childcare time and estimated total developmental childcare time that accounts for family structure, 2) between estimated total developmental childcare time that accounts for family structure and estimated total developmental childcare time that accounts for family structure and assortative mating, and 3) between estimated total developmental childcare time that accounts for family structure and assortative mating, and estimated total developmental childcare time that accounts for family structure, assortative mating, and specialization between partners. These Z-tests estimate whether the respective contributions of family structure, assortative mating, and specialization between partners towards class gaps in developmental childcare time are statistically significant. We also estimate a fourth set of Ztests that compare estimates of class gaps in maternal developmental childcare time to those in total developmental childcare time from our most detailed matching procedure, to understand how the combined effects of family structure, assortative mating, and specialization between partners

\footnotetext{
${ }^{5}$ Appendix Table 2 shows correlations between model variables among mothers in our analysis sample.
} 
affects class gaps in developmental childcare time. We will find evidence for increased class gaps in developmental childcare time if the coefficients corresponding to maternal education being a high school degree or less (as compared to the reference group of some college but no Bachelor's degree) and/or family income being below the 25th percentile (as compared to the reference group of family income within the 25th-75th income percentiles) significantly decrease between models, or if the coefficients corresponding to maternal education being a Bachelor's or higher and/or family income being above the 75 th income percentile (as compared to the same reference groups as above) significantly increase between models.

\section{Results}

\section{Comparisons of Class Gaps in Maternal and Total Developmental childcare Time}

Figure 1 shows average estimated developmental childcare time by maternal education across ATUS respondents who are mothers, for our various measures of childcare (as represented by differentcolored bars). Comparing across the clusters of bars (i.e., across levels of parental education), we see that accounting for family structure (in orange) certainly increases total parental time in developmental childcare across all levels of education relative to just measuring maternal developmental childcare time (in green). Further, accounting for family structure also appears to lead to slightly wider educational gaps in primary childcare in absolute terms. Additionally accounting for assortative mating (as seen in the blue bars) more clearly reveals wider educational gaps in total primary childcare time, as estimates of childcare time for households where mothers have less than a Bachelor's degree fall, while estimates of total primary childcare time for households where mothers have a Bachelor's degree or higher rise. Finally, additionally accounting for specialization (red bars) appears to slightly increase the magnitude of class gaps in total parental developmental childcare for children aged 0-6. The combined effects of family structure, assortative mating, and specialization, then, is to increase gaps in total parental childcare time by education.

Figure 2 shows these same figures where class is measured by family income rather than maternal education. Here, we see that compared to the income gradient in maternal time (green bars), the income gradient in total parental time after adjusting for family structure appears steeper (orange bars). Additionally accounting for assortative mating (blue bars) reveals moderately wider 
income-based gaps in total parental childcare time than only accounting for family structure: estimates of total childcare performed by parents in households below the 25th income percentile fall, while estimates of total childcare performed in households above the 25 th percentile rise. Finally, specialization (red bars) appears to only have a minor effect on these class gaps. As with maternal childcare, more fully accounting for family structure, assortative mating, and specialization appears to reveal wider income-based gaps in total parental childcare time.

\section{Regression Results}

In Table 3, we present the results of Z-tests that compare the coefficients on education and income in the estimates of our four regression models, each of which predicts a different measure of developmental childcare (unadjusted for parental copresence): maternal childcare time, total parental time after matching on family structure, total parental time after matching on family structure and assortative mating, and total parental time after matching on family structure, assortative mating, and specialization between partners. These Z-tests more rigorously test the contributions of the mechanisms of family structure, assortative mating, and specialization between partners towards class gaps in developmental childcare time, while disentangling the effects of parental education and income $^{6}$ in all regressions and accounting for potential confounders that may be correlated with developmental childcare time and these mechanisms. ${ }^{7}$

We find some evidence that accounting for family structure (Column 1) widens income-based gaps in total parental developmental childcare time between low-income and middle-income families, as compared to maternal developmental childcare time alone. This effect is likely due to the gaps in the presence of coresident partners between mothers in low- and middle-income households, as seen in Table 2. While this effect is only marginally significant, the magnitude of this estimated increase in developmental childcare time-about seven minutes per day-is large, given that Table 2 suggests mothers in middle-income households perform about eight more minutes of developmental childcare per day than mothers in low-income households. Surprisingly, though mothers of children aged 0-6 with a Bachelor's degree or higher are also more likely to live with a coresident partner than are

\footnotetext{
${ }^{6}$ Because maternal education and family income are somewhat collinear, we estimate the variance inflation factor (VIF) of the maternal education and family income variables to check that collinearity does not lead to increases in the standard errors of estimated regression coefficients. In all models, the VIF for these variables are below benchmark levels that indicate cause for concern.

${ }^{7}$ Appendix Table 3 contains full model results for these regressions, and Appendix Table 4 contains the results of Z-tests that compare all model coefficients.
} 
less-educated mothers, accounting for family structure does not significantly widen education-based gaps in developmental childcare time.

Turning to Column 2, we find that additionally accounting for assortative mating leads to substantively and significantly wider gaps in parental developmental childcare time based on maternal education, due to an increase in parental developmental childcare received by children aged 0-6 whose mothers have at least a Bachelor's degree. Assortative mating increase the gap in total parental childcare time received between children of college-educated mothers and children of high school-educated mothers by almost fifteen minutes per day. To put this gap in context, the effect of assortative mating is about as large as education-based gaps in maternal childcare time per day (see Table 1). In sum, the propensity of highly-educated mothers to live with partners who also provide large amounts of developmental childcare appears to drive wide inequality in total developmental childcare time. Meanwhile, assortative mating does not appear to widen income-based gaps in parental developmental childcare time. Finally, we see in Column 3 that accounting for economic specialization between partners does not significantly affect education- or income-based gaps in parental developmental childcare time.

Column 4 shows the sum effect of these three processes-family structure, assortative mating, and specialization between partners-on class gaps in parental developmental childcare time for parents of young children aged 0-6, as compared to maternal developmental childcare time. These processes combine to widen gaps in parental developmental childcare time of young children aged 0-6 based on maternal education by over twenty-seven minutes per day, compared to maternal developmental childcare time alone. Meanwhile, the gap between families in the lowest income quartile and families in the middle income quartiles in our measure of parental developmental childcare time that accounts for family structure, assortative mating, and specialization between partners is over eight minutes wider than the same gap in maternal childcare time, with this difference being statistically significant.

To better place these results in context, Figures 3 and 4 present predicted class gaps in parental developmental childcare time by maternal education and family income, respectively, for each of our four dependent variables: maternal time, parental time that accounts for family structure, parental time that additionally accounts for assortative mating, and parental time that additionally accounts for specialization between partners. In Figure 3, we see that, all else equal, mothers with a Bachelor's 
degree spend about seventeen more minutes per day in developmental childcare for their children aged 0-6 than do mothers with no more than a high school education. However, after accounting for family structure, assortative mating, and specialization between partners, this gap more than doubles to over 44 minutes per day, with most of the growth in this gap due to assortative mating. Figure 4 shows that mothers in high-income households perform about twelve more minutes per day in developmental childcare for their children aged 0-6 than mothers in low-income households. This gap widens to about seventeen minutes per day after accounting for family structure, assortative mating, and specialization between partners.

We also run models that predict class gaps in total parental developmental childcare time adjusted to discount childcare performed in the presence of one's partner. The results of these regression models, and the comparison of coefficients between these models, can be found in Appendix Tables D1 and D2, respectively (also see Appendix Figures D1-D4). We find a similar effect of assortative mating and economic specialization between partners on maternal education-based gaps in parental developmental childcare time towards young children aged 0-6, and that this accounts for most of the increased education-based gap in parental developmental childcare time as compared to maternal childcare time alone. However, after discounting childcare time where both partners are present, accounting for family structure no longer widens income-based gaps in childcare time received by young children aged 0-6. We interpret this finding to say that young children in middleand high-income households receive more childcare where both parents are present than do young children in low-income households.

\section{Discussion}

In recent decades, stark class divides have emerged in family structure, in the joint educational attainment and earnings of mothers and fathers, and parental developmental childcare time for young children. These features of unequal childhoods are likely to have consequences for inequality in child development. Because of the importance of child development for children's future attainment and well-being, inequality at home stands in the way of equal opportunity.

However, prior work has treated these features of familial inequality - family structure, assortative mating, and parental developmental childcare time - largely separately. We argue that estimates 
of class divides in maternal or paternal childcare time understate inequality in parental investment of time in children because family structure is sharply stratified by class and because marriages are homogamous along many dimensions. Further, childcare time in two-parent households may also be affected by the degree to which one parent specializes in childcare. Yet, existing research on class gaps in parental childcare time that has relied on the high-quality time diary data in the ATUS has not investigated these interconnections, in large part because only one household member fills out an ATUS time diary.

We overcome this limitation by using matching methods to generate synthetic parental dyads in the 2003-2018 ATUS, and find that previous measures of class gaps in maternal or paternal developmental childcare time understate the true extent of class inequality in total parental developmental childcare time. Further, we find that different demographic mechanisms drive income-based gaps than drive education-based gaps in total parental childcare time. There is some evidence that class gaps in family structure exacerbate income-based gaps in parental developmental childcare time as opposed to maternal childcare time, though only when considering our measure of time that is unadjusted for joint childcare time. However, we find clear evidence that assortative mating significantly and substantially widens gaps in total developmental childcare time by maternal education, whether or not we adjust for joint time in developmental childcare. In contrast, we find little evidence that specialization within the household might offset these class divides.

The sum result of accounting for these three processes is to more than double education-based gaps in total parental childcare time as compared to gaps based on maternal childcare time alone (44 minutes/day vs. 17 minutes/day), and to also widen income-based gaps in total parental developmental childcare time as compared to gaps in maternal childcare time (17 minutes/day vs. 12 minutes/day). Notably, the size of these estimated education-based gaps are substantially larger than what might be expected from simply summing the education-based gaps in maternal and paternal childcare time presented in Table 1 under the assumption of full educational homogamy, as has been done in previous studies (e.g., Altintas 2016). We view these findings as complementary to previous research that focuses on parental motivations or beliefs about child-rearing as key drivers of parental childcare time (e.g., Lareau 2003). Here, we focus instead on family composition and show that inequalities in family composition explain a substantial portion of income- and education-based gaps in total parental developmental childcare time. 
While our study focuses on parental time, children may also receive valuable investments of time from other kin. If kin support is more common for lower-SES children or in the context of non-marital households (e.g., Stack 1974), our results may overestimate class gaps in total childcare time. Because the information on family interrelationships in the ATUS only connects parents and children, we can only examine developmental childcare of household children performed by grandparents living in the household, and not other kin. As seen in Appendix Table 5, low-income and less-educated parents are more likely to live with their young child's grandparents, but few parents are in these living arrangements overall. Further, $89 \%$ of these grandparents perform no developmental childcare, with a mean of 10.2 minutes of developmental childcare performed by all grandparents. The result is that the effect of accounting for developmental childcare provided by coresidential grandparents on class gaps in developmental childcare received by young children aged 0-6 is negligible. However, our focus on childcare provided by household adults could still miss childcare that lower-SES children receive from nearby relatives, older household children, preschools, and care workers.

A second limitation of our study is that, while we match on observable characteristics that capture the constructs at the heart of family structure, assortative mating, and specialization, we cannot account for intra-parental negotiations or other unobservable factors that shape total parental developmental childcare time. It is unclear, however, that these unobservable factors would bias our estimates of education- or income-based gaps in total childcare time, in which we are primarily interested. To the extent the unobservable factors are correlated with parental education or income, then we expect that our procedure, which creates synthetic couples based on the actual educational attainment and income of both partners, will account for the effect of these unobservable factors on class gaps in total parental childcare time. If, however, unobservable factors that shape total parental childcare time are orthogonal to parental education or income, then they will not affect our estimates of class gaps.

Third, and relatedly, we do not directly observe total parental developmental childcare time received by household children, instead estimating this total parental developmental childcare time using matching methods. But, research that relies on the child-centered time diaries in the PSIDCDS also finds wide class gaps in the amount of time that children spend in the care of parents (Sandberg and Hofferth 2001; Hsin and Felfe 2014). Because of the difference in activity codes 
between the ATUS and PSID-CDS, and because the PSID-CDS time diaries are child- rather than parent-centric, direct comparison between our estimates of class gaps in total parental child care and those estimated from the PSID-CDS are problematic. That said, our results are consistent with previous work that relies on the PSID-CDS, and additionally identify the contribution of class gaps in family structure, assortative mating, and specialization between partners towards class gaps in childcare time.

We further test the validity of our matching method by applying it to the 2014-15 UK Time Use Survey (UKTUS), which collects 24-hour time diaries from both partners in a household, and thus allows us to see whether our matching method introduces bias in estimating the correlation between model variables and total parental childcare time. While differences between the ATUS and UKTUS make an apples-to-apples comparison impossible, we find that the relationships between model variables and our synthetic estimates of total parental childcare time is not significantly different than the relationships between model variables and actual total parental childcare time (see Appendix Table 6 for more details).

Fourth, it is not possible to rule out that the class gaps we observe in parental time in developmental childcare are caused by highly-educated and high-income parents over-reporting their childcare time in order to more closely approximate the ideals of intensive parenting. However, time diary data are acknowledged to have high reliability and validity (e.g., Gershuny et al. 2017). Indeed, research that finds social desirability bias among high-SES parents in parental responses about how often they read to their child measures this bias by comparing these responses to benchmark time-diary data on time spent reading to children (Hofferth 2006).

Fifth, our measure of developmental childcare time does not account for time coded as "physical care of children", or for other interactions with children that may be developmentally enriching for children. However, as shown in Appendix Table 7, there are similar class gaps in physical childcare time for young children as in developmental childcare time, and we find using our matching method that class gaps in total physical childcare time received by children are wider than gaps in maternal physical care. Future research could usefully employ our method to estimate class gaps in other forms of total parental time using the ATUS.

Finally, while we do not find that specialization between partners affects class gaps in total developmental parental childcare time, this result may stem from noise in our imputation of wages 
for respondents who do not have information on wages or weekly earnings. We test the robustness of this finding to only using the weekly hours worked of each partner to match based on specialization, and find a similar null result (see Appendix Table 8).

In sum, we document that class gaps in family structure widen income-based gaps in total parental childcare time received by household children, while the presence of class-based assortative mating leads to wider education-based gaps in total parental childcare time. Accounting for class gaps in family structure and class-based assortative mating thus reveals larger class gaps, whether measured by education or income, in total parental developmental childcare received by children than has been reported in previous literature that relies on individual time diaries. Given the strong association between this childcare time and child development, these results suggest that class gaps in family structure and the presence of assortative mating may contribute to inequality in child outcomes.

The policy implication of these results is by no means clear. Programs implemented to date to encourage marriage have not succeeded (Wood et al. 2014). Instead, policies designed to improve parental job quality and augment household financial resources may be more effective in helping lowincome parents clear normative bars to marriage (Edin and Kefalas 2005; Schneider 2011) and/or in fostering child development directly. Further, we show that is not just that higher income and more highly educated mothers are more likely to be married, but who they are married to, that counts for class gaps in parental investment. Assortative mating, not just marriage, plays an important role in widening class gaps in parental investment. While private investments in children may then be difficult to equalize, progressive public investment could serve to narrow these gaps (Jackson and Schneider 2019). 


\section{References}

Altintas, Evrim. 2016. "The Widening Education Gap in Developmental Child Care Activities in the United States, 1965-2013." Journal of Marriage and Family. 78: 26-42.

Bandura, Albert. 1977. Social Learning Theory. Oxford, England: Prentice-Hall.

Becker, Gary. 1981. A Treatise on the Family. Cambridge: Harvard University Press.

Bianchi, Suzanne, Philip Cohen, Sara Raley, and Kei Nomaguchi. 2004. "Inequality in Parental Investment in Child-Rearing: Expenditures, Time, and Health." In Social Inequality. Ed. Kathryn Neckerman. New York: Russell Sage Foundation Press.

Bianchi, Suzanne, John Robinson, and Melissa Milkie. 2006. The Changing Rhythms of American Family Life. New York: Russell Sage.

Bianchi, Suzanne. 2011. "Family Change and Time Allocation in American Families." ANNALS. 638: $21-44$.

Bonke, Jens and Gosta Esping-Andersen. 2011. "Family Investments in Children-Productivities, Preferences, and Parental Child Care." European Sociological Review 27(1): 43-55.

Cano, Tomàs. 2019. "Changes in Fathers' and Mothers' Time With Children: Spain, 2002-2010." European Sociological Review 35(5):616-636.

Cano, Tomás, Francisco Perales, and Janeen Baxter. 2019. "A Matter of Time: Father Involvement and Child Cognitive Outcomes." Journal of Marriage and Family 81(1):164-184.

Carlson, Marcia and Lawrence Berger. 2013. "What Kids Get from Parents: Packages of Parental Involvement across Complex Family Forms." Social Service Review 87(2): 213-249.

Cheadle, Jacob E. and Paul R. Amato. 2011. "A Quantitative Assessment of Lareau's Qualitative Conclusions About Class, Race, and Parenting." Journal of Family Issues. 32(5): 679-706.

Clogg, Clifford C., Eva Petkova, and Adamantios Hatirou. 1995. "Statistical Methods for Comparing Regression Coefficients Between Models." American Journal of Sociology 100(5):1261-93.

Connelly, Rachel and Jean Kimmel. 2009. "Spousal Influences on Parents' Non-Market Time Choices." Review of Economics of the Household 7: 361-394.

Connelly, Rachel and Jean Kimmel. 2010. The Time Use of Mothers in the United States at the Beginning of the 21st Century. Kalamazoo, MI: W.E. Upjohn Institute for Employment Research.

Cox, Martha J. and Blair Paley. 2003. "Understanding Families as Systems." Psychology and Neuroscience 12(5): 193-196.

Craig, Lyn, Abigail Powell, and Ciara Smyth. 2014. "Towards intensive parenting? Changes in the composition and determinants of mothers' and fathers' time with children 1992-2006." British Journal of Sociology 65(3):555-579.

Del Bono, Emilia, Marco Francesconi, Yvonne Kelly, and Amanda Sacker. 2016. "Early Maternal Time Investment and Early Child Outcomes." The Economic Journal 126(October):F96-F135.

Edin, Katherine and Maria Kefalas. 2005. Promises I Can Keep. Berkeley: University of California Press.

England, Paula and Anjula Srivastava. 2013. "Educational differences in US parents' time spent in child care: The role of culture and cross-spousal influence." Social Science Research. 42(4): 971-988. 
Fiorini, Mario and Michael P. Keane. 2014. "How the Allocation of Children's Time Affects Cognitive and Noncognitive Development." Journal of Labor Economics 32(4):787-836.

Folbre, Nancy, Jayoung Yoon, Kade Finnoff, and Allison Sidle Fuligni. 2005. "By What Measure? Family Time Devoted to Children in the United States." Demography. 42(2): 373-390.

Gershuny, Jonathan, Teresa Harms, Aiden Doherty, Emma Thomas, Karen Milton, Paul Kelly, and Charlie Foster. 2017. "CAPTURE24: Testing self-report time-use diaries against objective instruments in real time." Centre for Time Use Research working paper. Online link.

Gialamas, Angela, Dandara G. Haag, Murthy N. Mittinty, and John Lynch. 2019. "Which time investments in the first 5 years of life matter most for children's language and behavioural outcomes at school entry?" International Journal of Epidemiology. Online First.

Gibson-Davis, Christina and Heather Rackin. 2014. "Marriage or Carriage? Trends in Union Context and Birth Type by Education." Journal of Marriage and Family 76(3):506-519.

Gonalons-Pons, Pilar and Christine R. Schwartz. 2017. "Trends in Economic Homogamy: Changes in Assortative Mating or the Division of Labor in Marriage?" Demography 54(3):985-1005.

Guryan, Jonathan, Erik Hurst, and Melissa Kearney. 2008. "Parental Education and Parental Time with Children." Journal of Economic Perspectives. 22(3):23-46.

Gupta, Nabanita Datta and Leslie S. Stratton. 2008. "Institutions, Social Norms, and Bargaining Power: An Analysis of Individual Leisure Time in Couple Households." VCU School of Business, Department of Economics Working Papers. No. 806.

Heckman, James. 2006. "Skill Formation and the Economics of Investing in Disadvantaged Children." Science 312: 1900-1902.

Hofferth, Sandra L. 2006. "Response Bias in a Popular Indicator of Reading to Children." Sociological Methodology 36(1):301-315.

Hofferth, Sandra L., Sarah M. Flood, Matthew Sobek, and Daniel Backman. 2020. American Time Use Survey Data Extract Builder: Version 2.8 [dataset]. College Park, MD: University of Maryland, and Minneapolis, MN: University of Minnesota. (Online Link)

Hsin, Amy and Christina Felfe. 2014. "When Does Time Matter? Maternal Employment, Children's Time With Parents, and Child Development." Demography 51(5):1867-1894.

Iacus, Stefano M., Gary King, and Guiseppe Porro. 2012. "Causal Inference Without Balance Checking: Coarsened Exact Matching." Political Analysis 20(1):1-24.

Ishizuka, Patrick. 2019. "Social Class, Gender, and Contemporary Parenting Standards in the United States: Evidence from a National Survey Experiment." Social Forces 98(1):31-58.

Jackson, Margot and Daniel Schneider. 2019. "Public Investments, Private Investments and Class Gaps in Child Development." Paper Presented at 2019 Annual Meeting of Population Association of America.

Kalenkoski, Charlene, David Ribar, and Leslie Stratton. 2007. "The Effect of Family Structure on Parents' Child Care Time in the United States and the United Kingdom." Review of Economics of the Household 5: 353-384.

Kalil, Ariel, Rebecca Ryan, and Michael Corey. 2012. "Diverging Destinies: Maternal Education and the Developmental Gradient in Time With Children." Demography 49(4):1361-1383.

Kalil, Ariel, Rebecca Ryan, and Elise Chor. 2013. "Time Investments in Children across Family Structures." The ANNALS of the American Academy of Political and Social Science 654: 150168. 
Kendig, Sarah and Suzanne Bianchi. 2008. "Single, Cohabitating, and Married Mothers' Time With Children." Journal of Marriage and Family 70: 1228-1240.

Kornrich, Sabino and Frank Furstenberg. 2013. "Investing in Children: Changes in Parental Spending on Children, 1972-2007." Demography 50:1-23.

Lareau, Annette. 2003. Unequal Childhoods: Class, Race, and Family Life Berkeley, CA: University of California Press.

Lesthaeghe, Ron. 2010. "The Unfolding Story of the Second Demographic Transition." Population and Development Review 36(2):211-251.

Li, Angran and Daniel Hamlin. 2019. "Is Daily Parental Help with Homework Helpful? Reanalyzing National Data Using a Propensity Score-Based Approach." Sociology of Education 92(4):367385.

Macdonald, Kenneth I. 2011. "Family Investments in Children: What the Interactions and the Data Do Not Say." European Sociological Review 27(2):281-286.

Mahalanobis, Prasanta Chandra. 1936. "On the generalised distance in statistics." Proceedings of the National Institute of Sciences of India 2(1):49-55.

Mare, Robert D. 2016. "Educational Homogamy in Two Gilded Ages: Evidence from Intergenerational Social Mobility Data." The ANNALS of the American Academy of Political and Social Science 663(1):117-139.

Martin, Molly A. 2006. "Family structure and income inequality in families with children, 1976 to 2000." Demography 43(3):421-445.

McEwen, Craig A. and Bruce S. McEwen. 2017. "Social Structure, Adversity, Toxic Stress, and Intergenerational Poverty: An Early Childhood Model." Annual Review of Sociology 43:445472 .

McLanahan, Sara. 2004. "Diverging Destinies: How Children Are Faring under the Second Demographic Transition?" Demography 41(4): 607-27.

McHale, J.P. and Rasmussen, J.L. 1998. "Coparental and family group-level dynamics during infancy: Early Family Precursors of Child and Family Functioning During Preschool." Development and Psychopathology. 10: 39-59.

Milkie, Melissa A., Kei M. Nomaguchi, and Kathleen E. Denny. 2015. "Does the Amount of Time Mothers Spend With Children or Adolescents Matter?" Journal of Marriage and Family $77(2): 355-372$.

Parker, Kim, and Wendy Wang. 2013. Modern Parenthood: Roles of Moms and Dads Converge as They Balance Work and Family. Washington, DC: Pew Research Center.

Pepin, Joanna R., Liana C. Sayer, and Lynne M. Casper. 2018. "Marital Status and Mothers' Time Use: Childcare, Housework, Leisure, and Sleep." Demography 55(1):107-133.

Pollak, Robert A. 2005. "Bargaining Power in Marriage: Earnings, Wage Rates, and Household Production." NBER Working Paper No. 11239.

Price, Joseph and Ariel Kalil. 2018. "The Effect of Mother-Child Reading Time on Children's Reading Skills: Evidence from Natural Within-Family Variation." Child Development.

Raley, Sara, Suzanne M. Bianchi, and Wendy Wang. 2012. "When Do Fathers Care? Mothers' Economic Contribution and Fathers' Involvement in Child Care." American Journal of Sociology. 117(5):1422-1459. 
Ramey, Garey and Valerie Ramey. 2010. "The Rug Rat Race." Brookings Papers on Economic Activity Spring: 129-176.

Sandberg, John and Sandra Hofferth. 2001. "Changes in Children's Time with Parents: United States, 1981-1997." Demography 38(3): 423-436.

Sayer, Lianna, Suzanne Bianchi, and John Robinson. 2004. "Are Parents Investing Less in Children? Trends in Mothers' and Fathers' Time with Children." American Journal of Sociology. 110(1): $1-43$.

Schneider, Daniel. 2011. "Wealth and the Marital Divide." American Journal of Sociology 117(2): 627-667.

Schneider, Daniel, Orestes Hastings, and Joe LaBriola. 2018. "Income Inequality and Class Divides in Parental Investment." American Sociological Review 83(3):475-507.

Schwartz, Christine and Robert Mare. 2005 "Trends in Educational Assortative Marriage from 1940 to 2003." Demography 42(4):621-646.

Schwartz, Christine. 2010. "Earnings Inequality and the Changing Association between Spouses' Earnings." American Journal of Sociology 115(5):1524-1557.

Schwartz, Christine. 2013. "Trends and Variation in Assortative Mating: Causes and Consequences." Annual Review of Sociology 39: 451-470.

Shen, Jenny. 2019. "(Non-)Marital Assortative Mating and the Closing of the Gender Gap in Education." Working paper. Online link.

Stack, Carol. 1974. All Our Kin: Strategies for Survival in a Black Community. New York: Basic Books.

Villena-Roldán, Benjamín and Ceclilia Ríos-Aguilar. 2011. "Causal Effects of Maternal TimeInvestment on Children's Cognitive Outcomes." Working paper. December 18.

Vinopal, Katie and Seth Gershenson. 2017. "Re-Conceptualizing Gaps by Socioeconomic Status in Parental Time with Children." Social Indicators Research 133:623-643.

Wood, Robert, Quinn Moore, Andrew Clarkwest, and Alexandra Killewald. 2014. "The Long-Term Effects of Building Strong Families: A Program for Unmarried Parents." Journal of Marriage and Family 76: 446-463. 
Table 1. Developmental Childcare Time and Partnership by Parental Gender, Education, and Coresidence with Children

$\begin{array}{rr}\% \text { Coresident } & \text { Developmental } \\ \text { with Partner } & \text { Childcare (mins/day) }\end{array}$

Mothers living with own children

HS/GED or less

$68.1 \%$

$73.0 \%$

46.0

Some college, no BA

$92.7 \%$

48.0

BA or more

$92.5 \%$

61.1

Fathers living with own children

HS/GED or less

$94.4 \%$

32.7

Some college, no BA

$98.6 \%$

35.7

BA or more

41.5

Fathers with own non-household children

HS/GED or less

1.7

Some college, no BA

11.7

$\mathrm{BA}$ or more

18.3 
Table 2. Developmental Childcare Time and Partnership by Parental Gender and Family Income

\begin{tabular}{lrr}
\hline & $\begin{array}{r}\text { \% Coresident } \\
\text { with Partner }\end{array}$ & $\begin{array}{r}\text { Developmental } \\
\text { Childcare (mins/day) }\end{array}$ \\
\hline & & \\
Mothers living with own children & & \\
0-25th HH income percentile & $55.3 \%$ & 53.1 \\
25th-75th HH income percentile & $83.2 \%$ & 53.3 \\
75th + HH income percentile & $93.8 \%$ & 58.6 \\
Fathers living with own children & & \\
0-25th HH income percentile & $90.1 \%$ & 32.1 \\
25th-75th HH income percentile & $95.3 \%$ & 36.3 \\
75th + HH income percentile & $98.3 \%$ & 40.0 \\
\hline
\end{tabular}


Table 3: Comparison of Regression Coefficients for Different DVs of Developmental Childcare Time

\begin{tabular}{lcccc}
\hline Model Comparison & $\begin{array}{c}\text { Model 2 - } \\
\text { Model 1 }\end{array}$ & $\begin{array}{c}\text { Model 3 - } \\
\text { Model 2 }\end{array}$ & $\begin{array}{c}\text { Model 4 - } \\
\text { Model 3 }\end{array}$ & $\begin{array}{c}\text { Model 4 - } \\
\text { Model 1 }\end{array}$ \\
\hline HS/GED or less & -0.57 & -4.18 & -1.91 & $-6.65^{*}$ \\
Some college, no BA & $\begin{array}{c}(-0.18) \\
\text { ref. }\end{array}$ & $\begin{array}{c}(-1.04) \\
\text { ref. }\end{array}$ & $\begin{array}{c}(-0.50) \\
\text { ref. }\end{array}$ & $\begin{array}{c}(-2.05) \\
\text { ref. }\end{array}$ \\
BA or higher & 3.28 & $10.16^{*}$ & 7.04 & $20.48^{* * *}$ \\
0-25th pctile & $(0.85)$ & $(2.35)$ & $(1.56)$ & $(5.08)$ \\
25-75th pctile & $-6.71^{+}$ & -1.82 & 0.19 & $-8.34^{* *}$ \\
& $(-1.85)$ & $(-0.46)$ & $(0.05)$ & $(-2.25)$ \\
75-100th pctile & ref. & ref. & ref. & ref. \\
& 0.86 & 0.99 & -5.06 & -3.22 \\
& $(0.22)$ & $(0.22)$ & $(-1.08)$ & $(-0.76)$ \\
\hline
\end{tabular}

Z-scores in parentheses

$+p<.1,{ }^{*} p<.05,{ }^{* *} p<.01,{ }^{* * *} p<.001$

Note: The dependent variables in Models 1-4 are: 1) maternal childcare time, 2) total parental childcare time after accounting for family structure, 3) total parental childcare time after accounting for family structure and assortative mating, and 4) total parental childcare time after accounting for family structure, assortative mating, and specialization between partners. 
Figure 1: Comparison of Maternal Education-Based Gaps in Developmental Childcare Time, by Matching Procedure

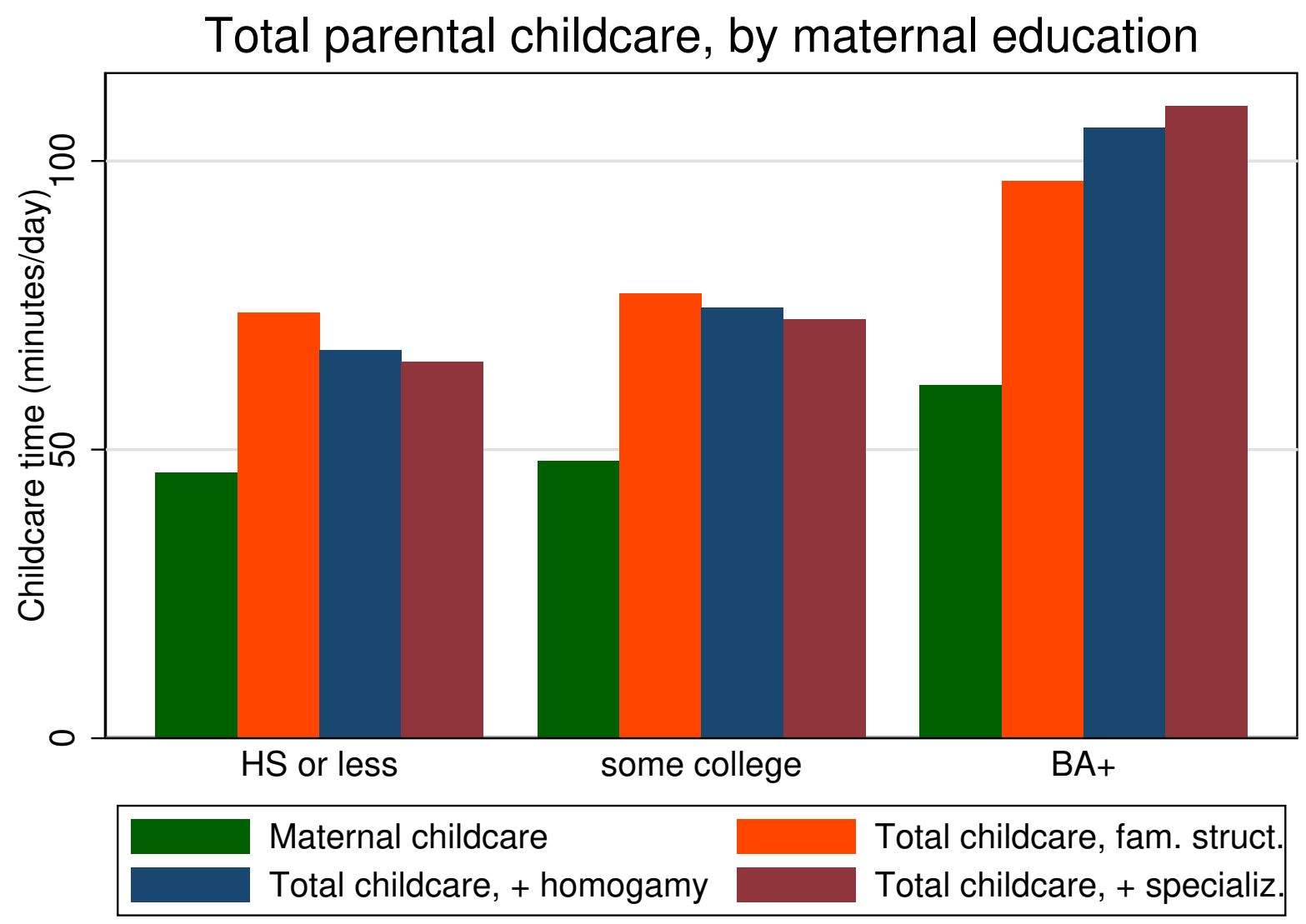


Figure 2: Comparison of Family Income-Gaps in Developmental Childcare Time, by Matching Procedure

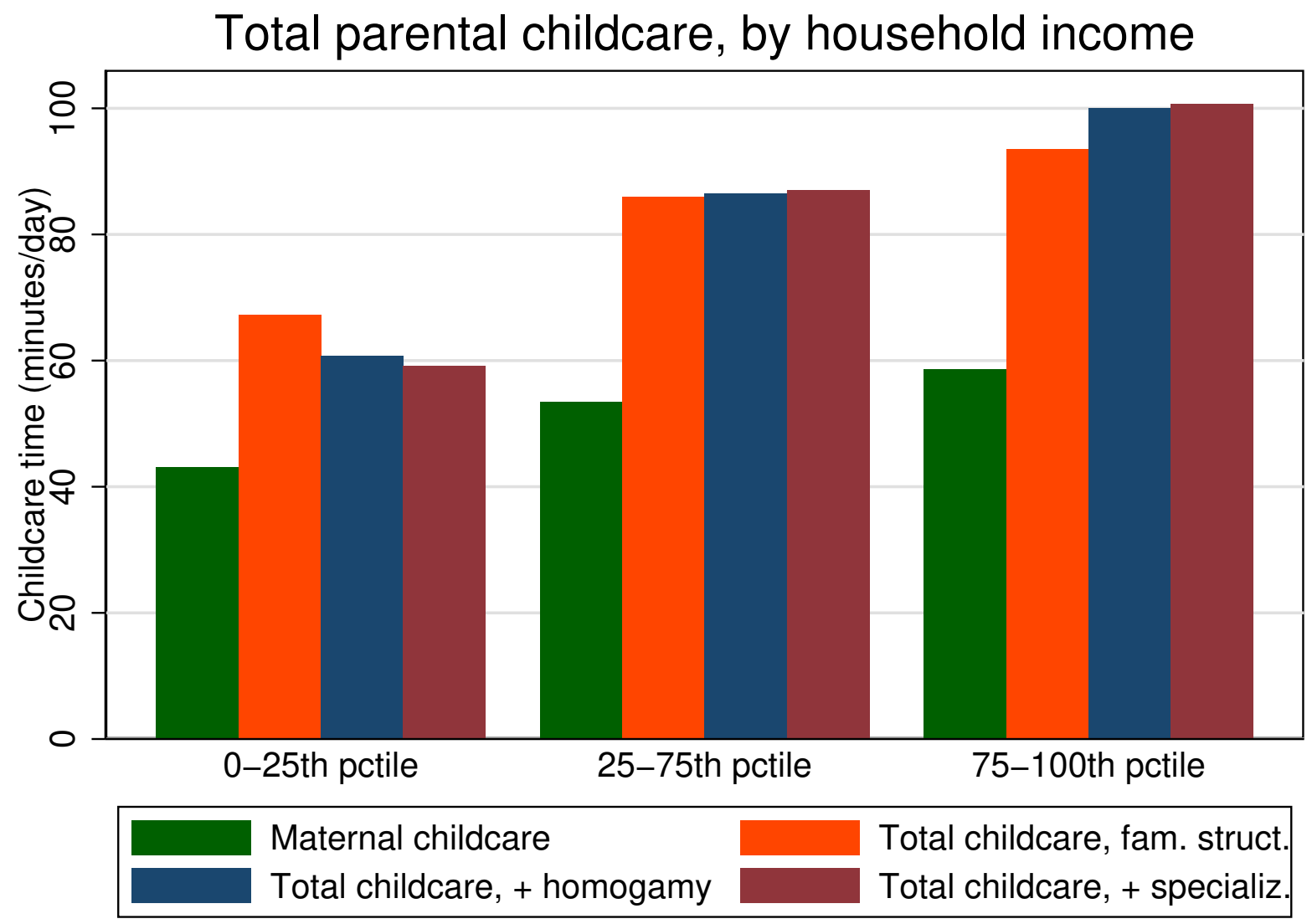




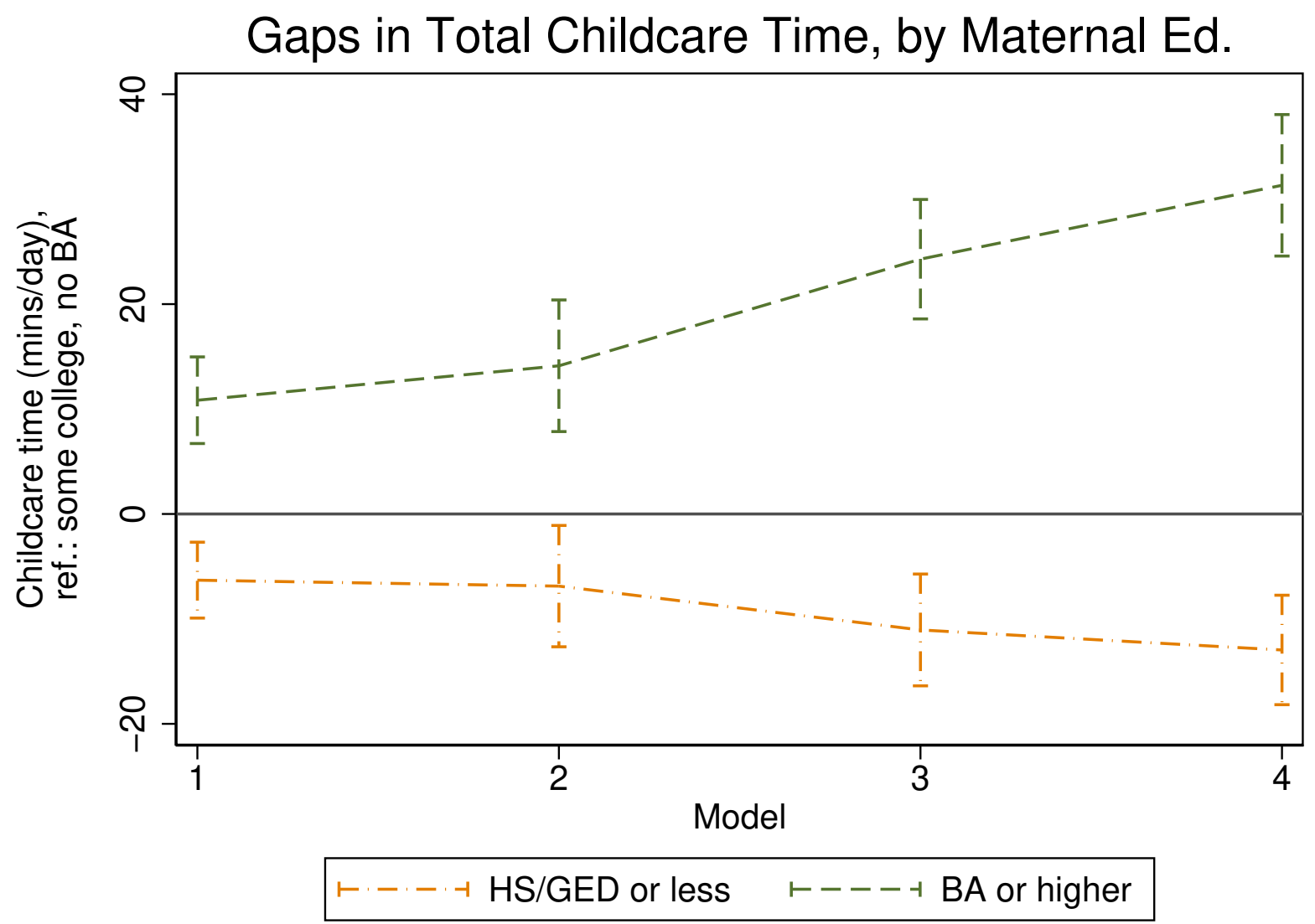

Note: The dependent variables in Models 1-4 are: 1) maternal childcare time, 2) total parental childcare time after accounting for family structure, 3) total parental childcare time after accounting for family structure and assortative mating, and 4) total parental childcare time after accounting for family structure, assortative mating, and specialization between partners. 


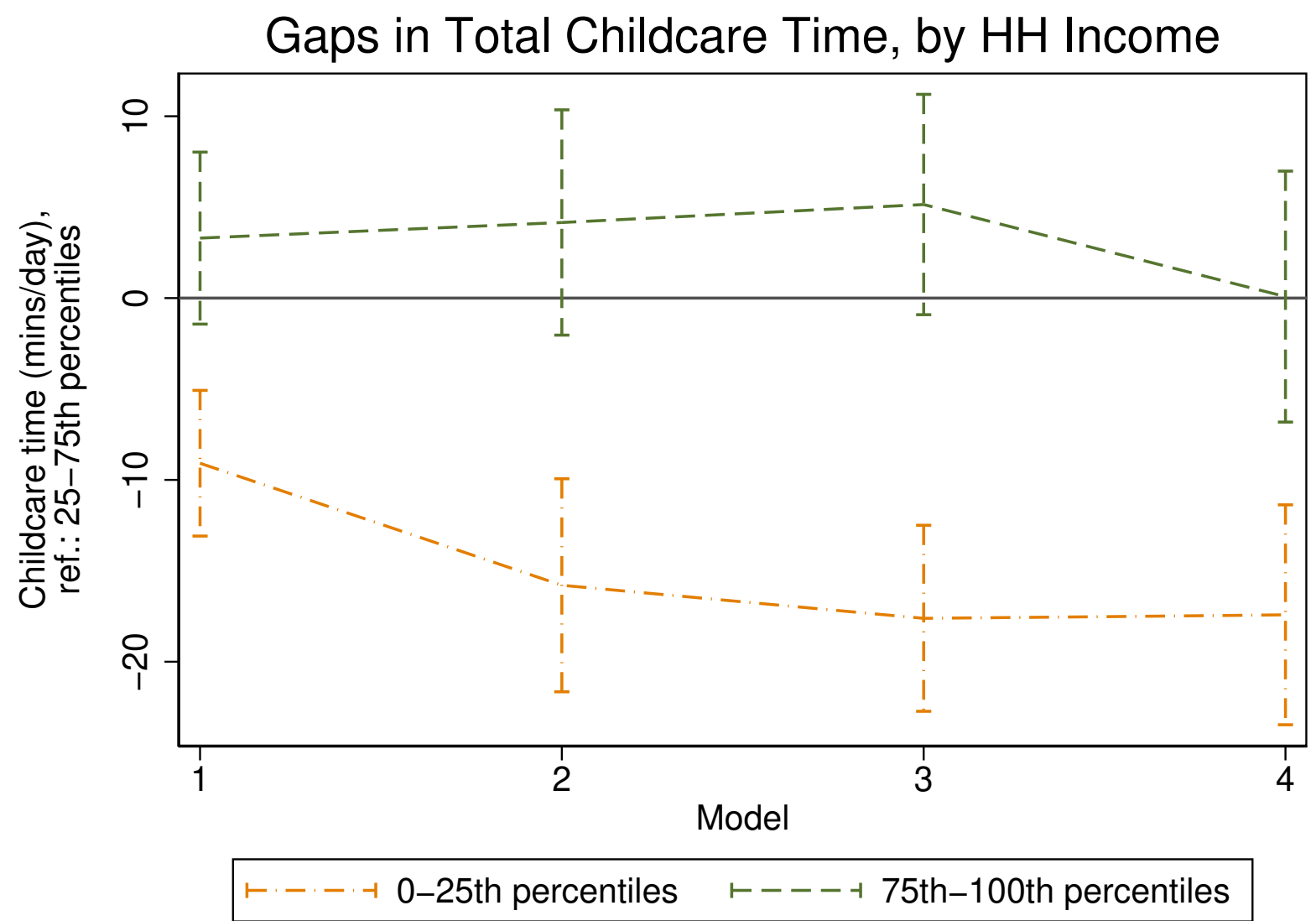

Note: The dependent variables in Models 1-4 are: 1) maternal childcare time, 2) total parental childcare time after accounting for family structure, 3) total parental childcare time after accounting for family structure and assortative mating, and 4) total parental childcare time after accounting for family structure, assortative mating, and specialization between partners. 


\section{Appendix Table 1: Coarsening of Variables Used in Matching Procedure}

\begin{tabular}{|c|c|c|}
\hline Variable & Uncoarsened Measurement & Coarsened Measurement \\
\hline \multicolumn{3}{|l|}{ Family Structure } \\
\hline $\begin{array}{l}\text { Number of household children un- } \\
\text { der } 18\end{array}$ & Exact number & 1,2, or $3+$ \\
\hline Age of youngest household child & Exact number & $0-1,2-3,4-6$ \\
\hline \multicolumn{3}{|l|}{ Assortative Mating } \\
\hline Age of parent & Exact number & $\begin{array}{l}\text { Approximate terciles: } 18-31,31-37 \text {, } \\
38+\end{array}$ \\
\hline Parental race & White / other & White / other \\
\hline Parental education & Years of education & $\begin{array}{l}\text { HS/GED or less, Some college but } \\
\text { no Bachelor's degree, Bachelor's de- } \\
\text { gree or greater }\end{array}$ \\
\hline Household income & $\begin{array}{l}\text { Midpoint of ATUS income cate- } \\
\text { gories, adjusted for inflation }\end{array}$ & $\begin{array}{l}0-25 \text { th percentile, } 25-75 \text { th per- } \\
\text { centile, } 75-100 \text { th percentile }\end{array}$ \\
\hline \multicolumn{3}{|l|}{ Specialization } \\
\hline Usual hours worked per week & Exact number & $0,1-34,35+$ \\
\hline $\begin{array}{l}\text { Log relative wages between respon- } \\
\text { dent and partner }\end{array}$ & Exact number & $\begin{array}{l}\text { Less than or equal to } 0, \text { greater than } \\
0\end{array}$ \\
\hline
\end{tabular}




\section{Appendix Table 2: Correlations Between Model Variables, Maternal Respondents}

\begin{tabular}{cccccccccc}
\hline & $(1)$ & $(2)$ & $(3)$ & $(4)$ & $(5)$ & $(6)$ & $(7)$ & $(8)$ & $(9)$ \\
\hline$(1)$ & 1.00 & & & & & & & & \\
$(2)$ & 0.10 & 1.00 & & & & & & & \\
$(3)$ & 0.08 & 0.54 & 1.00 & & & & & & \\
$(4)$ & 0.09 & -0.02 & -0.01 & 1.00 & & & & & \\
$(5)$ & -0.17 & -0.01 & 0.03 & -0.38 & 1.00 & & & & \\
$(6)$ & -0.01 & 0.28 & 0.36 & -0.12 & 0.37 & 1.00 & & & \\
$(7)$ & 0.07 & 0.00 & 0.10 & 0.02 & 0.01 & 0.05 & 1.00 & & \\
$(8)$ & -0.14 & 0.23 & 0.17 & -0.13 & 0.10 & 0.09 & 0.01 & 1.00 & \\
$(9)$ & -0.02 & -0.02 & -0.02 & -0.01 & -0.00 & -0.01 & -0.01 & 0.00 & 1.00
\end{tabular}

Variable key: (1) developmental childcare, minutes/day; (2) years of education; (3) family income (\$s); (4) number of household children aged 0-6; (5) age of youngest household child; (6) age of mother; (7) indicator for whether mother is White; (8) indicator for whether mother is employed; (9) indicator for whether time diary was filled out on weekend. 
Appendix Table 3: Full Regression Results, Unadjusted Measures of Total Parental Time

\begin{tabular}{|c|c|c|c|c|}
\hline & (1) & $(2)$ & (3) & (4) \\
\hline HS/GED or less & $\begin{array}{c}-6.31^{* * *} \\
(1.85)\end{array}$ & $\begin{array}{l}-6.87^{*} \\
(2.95)\end{array}$ & $\begin{array}{c}-11.05^{* * *} \\
(2.72)\end{array}$ & $\begin{array}{c}-12.96^{* * *} \\
(2.66)\end{array}$ \\
\hline Some college, no BA & ref. & ref. & ref. & ref. \\
\hline BA or higher & $\begin{array}{c}10.84^{* * *} \\
(2.11)\end{array}$ & $\begin{array}{c}14.12^{* * *} \\
(3.20)\end{array}$ & $\begin{array}{c}24.28^{* * *} \\
(2.90)\end{array}$ & $\begin{array}{c}31.32^{* * *} \\
(3.44)\end{array}$ \\
\hline $0-25$ th pctile & $\begin{array}{c}-9.08^{* * *} \\
(2.04)\end{array}$ & $\begin{array}{c}-15.80^{* * *} \\
(2.99)\end{array}$ & $\begin{array}{c}-17.61^{* * *} \\
(2.61)\end{array}$ & $\begin{array}{c}-17.42^{* * *} \\
(3.09)\end{array}$ \\
\hline 25-75th pctile & ref. & ref. & ref. & ref. \\
\hline 75-100th pctile & $\begin{array}{c}3.30 \\
(2.41)\end{array}$ & $\begin{array}{c}4.16 \\
(3.16)\end{array}$ & $\begin{array}{l}5.16^{+} \\
(3.09)\end{array}$ & $\begin{array}{c}0.08 \\
(3.52)\end{array}$ \\
\hline \# HH children aged 0-7 & $\begin{array}{c}1.44 \\
(1.40)\end{array}$ & $\begin{array}{l}5.13^{*} \\
(2.04)\end{array}$ & $\begin{array}{l}5.86^{* *} \\
(1.95)\end{array}$ & $\begin{array}{l}1.61 \\
(2.15)\end{array}$ \\
\hline Youngest child age & $\begin{array}{c}-5.55^{* * *} \\
(0.39)\end{array}$ & $\begin{array}{c}-8.71^{* * *} \\
(0.62)\end{array}$ & $\begin{array}{c}-9.52^{* * *} \\
(0.58)\end{array}$ & $\begin{array}{c}-9.11^{* * *} \\
(0.58)\end{array}$ \\
\hline Maternal age & $\begin{array}{c}0.11 \\
(0.15)\end{array}$ & $\begin{array}{l}0.39^{+} \\
(0.22)\end{array}$ & $\begin{array}{c}0.31 \\
(0.19)\end{array}$ & $\begin{array}{c}0.28 \\
(0.19)\end{array}$ \\
\hline Mother is White & $\begin{array}{c}12.97^{* * *} \\
(1.84)\end{array}$ & $\begin{array}{c}19.12^{* * *} \\
(2.78)\end{array}$ & $\begin{array}{c}22.67^{* * *} \\
(2.28)\end{array}$ & $\begin{array}{c}23.79^{* * *} \\
(2.55)\end{array}$ \\
\hline Mother is employed & $\begin{array}{c}-30.70^{* * *} \\
(1.75)\end{array}$ & $\begin{array}{c}-33.47^{* * *} \\
(2.57)\end{array}$ & $\begin{array}{c}-34.21^{* * *} \\
(2.41)\end{array}$ & $\begin{array}{c}-33.07^{* * *} \\
(2.58)\end{array}$ \\
\hline Weekend diary & $\begin{array}{c}-2.80^{* *} \\
(1.34)\end{array}$ & $\begin{array}{c}7.19^{* * *} \\
(2.23)\end{array}$ & $\begin{array}{c}6.72^{* * *} \\
(1.78)\end{array}$ & $\begin{array}{c}9.62^{* * *} \\
(2.18)\end{array}$ \\
\hline Observations & 16716 & 16716 & 15023 & 11131 \\
\hline
\end{tabular}




\section{Appendix Table 4: Comparison of Regression Coefficients Between Models in Ap- pendix Table 3, Full Model Results}

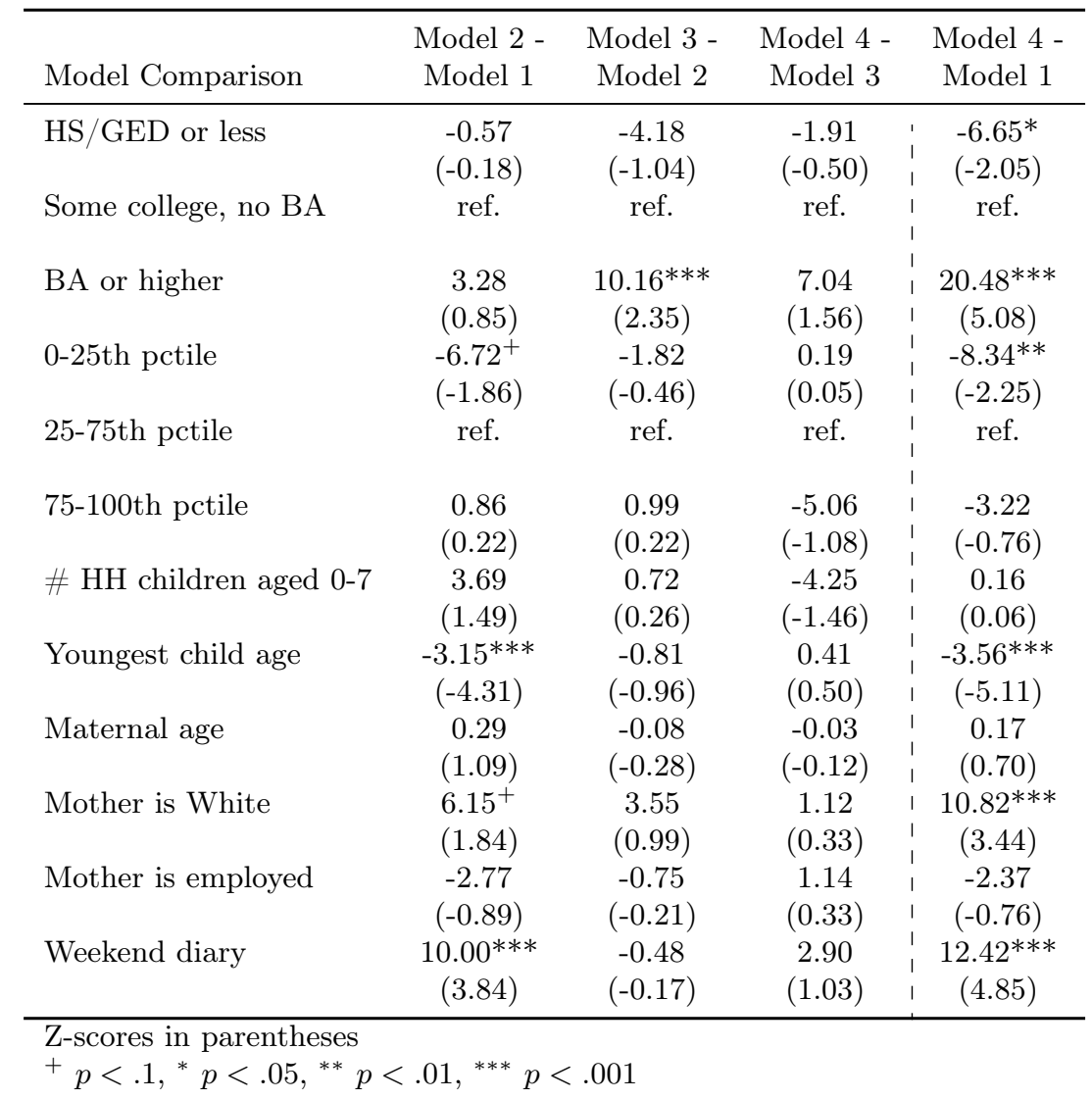

Note: The dependent variables in Models 1-4 are: 1) maternal childcare time, 2) total parental childcare time after accounting for family structure, 3) total parental childcare time after accounting for family structure and assortative mating, and 4) total parental childcare time after accounting for family structure, assortative mating, and specialization between partners. 
Appendix Table 5: Developmental Childcare Provided by Household Grandparents, by Education and Income

\begin{tabular}{llll}
\hline \hline Parental Education & \% Living With Parents & $\begin{array}{l}\text { Developmental Childcare } \\
\text { by HH Grandparents (min/day) }\end{array}$ & $\begin{array}{l}\text { Average Developmental Childcare } \\
\text { by HH Grandparents (min/day) }\end{array}$ \\
\hline HS/GED or less & $9.3 \%$ & 10.2 & 0.9 \\
Some college, no BA & $7.3 \%$ & 10.2 & 0.7 \\
BA + & $2.6 \%$ & 10.2 & 0.3 \\
\hline & & \\
\hline & & & Average Developmental Childcare \\
Family Income & \% Living With Parents & Developmental Childcare & by HH Grandparents (min/day) \\
& & by HH Grandparents (min/day) & 0.8 \\
Lowest income quartile & $8.2 \%$ & 10.2 & 0.6 \\
Middle income quartiles & $6.5 \%$ & 10.2 & 0.5 \\
Top income quartile & $4.7 \%$ & 10.2 & \\
\hline
\end{tabular}




\section{Appendix Table 6: Comparison of Regression Coefficients in Predicting Total Child- care Time in the UKTUS, Actual vs. Synthetic Couples}

\begin{tabular}{lccc}
\hline & Actual Couples & Synthetic Couples & Difference \\
\hline Above secondary education & $14.44^{* * *}$ & $20.65^{* * *}$ & -6.20 \\
(ref.: completed secondary or less) & $(3.91)$ & $(4.31)$ & $(-1.06)$ \\
\# HH children under 13 & $-4.87^{*}$ & -3.53 & -1.34 \\
& $(2.27)$ & $(2.47)$ & $(-0.40)$ \\
Youngest HH child aged 5-12 & $-55.96^{* * *}$ & $-60.59^{* * *}$ & 4.64 \\
(ref.: aged 0-4) & $(4.11)$ & $(4.58)$ & $(0.75)$ \\
Maternal age & 0.38 & $0.67^{*}$ & -0.30 \\
& $(0.24)$ & $(0.27)$ & $(-0.81)$ \\
Working, not full-time & -6.60 & $-11.81^{*}$ & 5.20 \\
(ref.: not in paid work) & $(4.69)$ & $(5.22)$ & $(0.74)$ \\
Working, full-time & $-15.45^{* *}$ & $-18.25^{* *}$ & 2.80 \\
(ref.: not in paid work) & $(4.95)$ & $(5.58)$ & $(0.38)$ \\
Weekend diary & 18.04 & $20.52^{* *}$ & -2.48 \\
& $(4.07)$ & $(4.35)$ & $(-0.42)$ \\
\hline Observations & 1322 & 951 & 951 \\
\hline Standard errors in parentheses in Columns 1 and $2 ;$ Z-scores in parentheses in Column 3. \\
$+p<.1,{ }^{*} p<.05,{ }^{* *} p<.01,{ }^{* * *} p<.001$ & &
\end{tabular}

Note: There are several important differences in the matching procedure performed on the UKTUS, compared to that in the ATUS. One major difference is that the UKTUS does not contain a race variable. A second difference is that, due to sample size constraints, we were not able to match on the UKTUS' three-category income variable. The coarsened exact matching in the UKTUS matched on weekend diary, age of youngest child (0-4 vs. 5-12), number of household children under 13 (1, 2, or $3+$ ), age (under 38 / over 39 for men; under 36 / over 37 for women), education (completed secondary or less / above secondary education), and employment status (not in paid work, working not full-time, working full-time). 
Appendix Table 7: Comparison of Regression Coefficients for Different DVs of Physical Childcare Time

\begin{tabular}{|c|c|c|c|c|}
\hline & (1) & $(2)$ & (3) & (4) \\
\hline HS/GED or less & $\begin{array}{c}-5.25^{* *} \\
(1.68)\end{array}$ & $\begin{array}{l}-5.59^{*} \\
(2.34)\end{array}$ & $\begin{array}{c}-11.11^{* * *} \\
(2.06)\end{array}$ & $\begin{array}{c}-7.61^{* *} \\
(2.46)\end{array}$ \\
\hline Some college, no BA & ref. & ref. & ref. & ref. \\
\hline BA or higher & $\begin{array}{c}6.42^{* * *} \\
(1.90)\end{array}$ & $\begin{array}{c}8.87^{* * *} \\
(2.55)\end{array}$ & $\begin{array}{c}16.30^{* * *} \\
(2.35)\end{array}$ & $\begin{array}{c}20.87^{* * *} \\
(2.40)\end{array}$ \\
\hline $0-25$ th pctile & $\begin{array}{l}-2.68 \\
(1.90)\end{array}$ & $\begin{array}{c}-8.12^{* *} \\
(2.51)\end{array}$ & $\begin{array}{c}-8.05^{* * *} \\
(2.30)\end{array}$ & $\begin{array}{l}-7.32^{*} \\
(2.98)\end{array}$ \\
\hline 25-75th pctile & ref. & ref. & ref. & ref. \\
\hline 75-100th pctile & $\begin{array}{l}5.75^{* *} \\
(2.13)\end{array}$ & $\begin{array}{l}6.57^{*} \\
(2.66)\end{array}$ & $\begin{array}{c}9.70^{* * *} \\
(2.44)\end{array}$ & $\begin{array}{l}6.73^{* *} \\
(2.45)\end{array}$ \\
\hline Controls & Yes & Yes & Yes & Yes \\
\hline Observations & 16716 & 16716 & 15023 & 11131 \\
\hline
\end{tabular}




\section{Appendix Table 8: Comparison of Regression Coefficients for Different DVs of Devel-}

opmental Childcare, Specialization Measured Only with Weekly Hours Worked

\begin{tabular}{|c|c|c|c|c|}
\hline Model Comparison & $\begin{array}{l}\text { Model } 2 \text { - } \\
\text { Model } 1\end{array}$ & $\begin{array}{l}\text { Model } 3 \text { - } \\
\text { Model } 2\end{array}$ & $\begin{array}{c}\text { Model } 4 \text { - } \\
\text { Model } 3\end{array}$ & $\begin{array}{c}\text { Model } 4 \text { - } \\
\text { Model } 1\end{array}$ \\
\hline HS/GED or less & $\begin{array}{l}-0.62 \\
(-0.23)\end{array}$ & $\begin{array}{l}-4.13 \\
(-1.48)\end{array}$ & $\begin{array}{l}-0.20 \\
(-0.86)\end{array}$ & $\begin{array}{l}-4.94^{*} \\
(-2.01)\end{array}$ \\
\hline Some college, no BA & ref. & ref. & ref. & ref. \\
\hline BA or higher & $\begin{array}{c}3.16 \\
(1.03)\end{array}$ & $\begin{array}{c}10.32^{* * *} \\
(3.66)\end{array}$ & $\begin{array}{l}5.00^{*} \\
(2.02)\end{array}$ & $\begin{array}{cc}18.48^{* * *} \\
(6.68)\end{array}$ \\
\hline $0-25$ th pctile & $\begin{array}{l}-6.85^{*} \\
(-2.26)\end{array}$ & $\begin{array}{l}-1.71 \\
(-0.62)\end{array}$ & $\begin{array}{l}-1.01 \\
(-0.43)\end{array}$ & $\begin{array}{c}-9.56^{* * *} \\
(-3.60)\end{array}$ \\
\hline 25-75th pctile & ref. & ref. & ref. & ref. \\
\hline 75-100th pctile & $\begin{array}{c}0.73 \\
(0.22)\end{array}$ & $\begin{array}{l}1.13 \\
(0.40)\end{array}$ & $\begin{array}{l}-3.71 \\
(-1.42)\end{array}$ & $\begin{array}{l}-1.87 \\
(-0.60)\end{array}$ \\
\hline
\end{tabular}

Z-scores in parentheses

$+p<.1,{ }^{*} p<.05,{ }^{* *} p<.01,{ }^{* * *} p<.001$

Note: The dependent variables in Models 1-4 are: 1) maternal childcare time, 2) total parental childcare time after accounting for family structure, 3) total parental childcare time after accounting for family structure and assortative mating, and 4) total parental childcare time after accounting for family structure, assortative mating, and specialization between partners. 


\section{Appendix A: Estimating Relative Wages Between Partners}

Respondents in the ATUS who report being paid hourly report their wages; thus, for these respondents, we are able to measure wages directly. For respondents who are working and not paid hourly, and for employed partners (whose wages are not provided in the ATUS), we estimate hourly wages by dividing usual weekly earnings by usual hours worked per week. For respondents and partners who are not employed, we use the standard Heckman (1979) twostage method to estimate counterfactual wages. First, we predict the probability of employment as a function of age, age squared, race (White/other), number of household children, years of education, survey year, and the state-level employment rate. Second, we use this probability to predict counterfactual wages in a regression framework that includes all variables in the first step except for the number of household children under 18.

We only observe hourly wages for ATUS respondents who report getting paid hourly, and we do not observe hourly wages for ATUS partners. Therefore, we estimate hourly wages for workers by dividing usual weekly earnings by usual hours worked per week, both variables which are available for both respondents and their partners. However, this does not allow us to estimate counterfactual wages for respondents and partners who are not employed. We use the Heckman (1979) two-stage method to estimate the wages of non-working respondents. First, we use a probit regression to predict the probability that a respondent or partner is employed based on the number of children in the household under the age of 18, age, age squared, years of education, year of survey, and state-level unemployment rate:

$$
\operatorname{Prob}\left(D_{i}=1 \mid Z_{i}\right)=\Phi\left(Z_{i} \gamma\right)+\epsilon,
$$

where $D_{i}$ equals 1 if the respondent (or partner) is employed and 0 if not, and $Z_{i}$ is the vector of controls listed above.

Second, we use a standard transformation of the predicted probabilities of working as an additional variable to predict the individual's wage, alongside the respondents' age, age squared, years of education, year of survey, and state-level unemployment rate:

$$
E\left[w_{i} \mid X_{i}, D_{i}=1\right]=X_{i} \beta+\rho \sigma_{u} \lambda(Z \gamma)+u
$$

where $w_{i}$ is a measure of wages, $X_{i}$ is a vector of the above controls, $\rho$ is the correlation between the unobserved determinants of the probability to work $\epsilon$ and the unobserved determinants of wages $u, \sigma_{u}$ is the standard deviation of $\mathrm{u}$, and $\lambda(Z \gamma)$ is the inverse Mills ratio evaluated at $Z \gamma$.

In all cases, we winsorize hourly wages at a floor of $\$ 5$ per hour and a ceiling of $\$ 99.99$ per hour (the maximum value of hourly wages reported in the CPS and ATUS). We then follow Connelly and Kimmel (2009) by using the log ratio of hourly wages of the respondent to hourly wages of their partner as a measure of relative wages for matching. As before, we match relative wages from the perspective of the respondent to relative wages from the perspective of potential alters' partners.

\section{References}

Connelly, Rachel and Jean Kimmel. 2009. "Spousal Influences on Parents' Non-Market Time Choices." Review of Economics of the Household. 7: 361-394.

Heckman, James. 1979. "Sample Selection Bias as a Specification Error." Econometrica. 47(1):153-161. 


\section{Appendix B: Reweighting of Estimates of Total Parental Childcare Time}

We perform two separate reweighting procedures in our analysis. Our first reweighting, which we perform before our matching procedure, is designed to account for any bias based on observable demographic characteristics from dropping parental observations that have low-quality time diaries or have missing values for household income. We use the Stata package survwgt (Winter 2002), which implements a commonly-used raking procedure (Deming and Stephan 1940) to iteratively adjust the weights until the marginal distribution of the demographic variables in the smaller sample is equal to that in the original sample. We reweight here using the coarsened variables for sex, whether a parent is white, educational attainment (HS/GED or less, some college but no Bachelor's, or a Bachelor's degree or higher), and parental age (18-31, 32-37, and 38+).

Second, after creating synthetic couples but before estimating our models, we reweight to account for observations that do not find matches in the coarsened matching procedure. While all maternal respondents find matched alters when matching on variables related to family structure, about $10 \%$ of mothers do not find a match when we additionally match on variables associated with assortative mating, and about $23 \%$ of mothers do not find a match when additionally matching on variables associated with specialization between partners. This may bias the conclusions drawn from comparing class gaps in total parental childcare time if, for example, the highly-educated mothers who are not matched differ systematically from the highly-educated mothers who are matched on observable characteristics. Here, we use the Stata package calibrate (D'Souza 2011) to reweight both a) the sample of mothers who have matches after coarsened matching on variables related to family structure and assortative mating (the "assortative mating sample"), and b) the sample of mothers who have matches after coarsened matching on variables related to family structure, assortative mating, and specialization (the "specialization sample") to match the population totals of several variables in the sample of mothers that remains after the first reweighting procedure. We create these calibration weights based on: total parental developmental childcare time that is estimated from matching based on family structure (which ensures that our estimates of total parental developmental childcare time in the assortative mating sample and specialization sample are on average equal to those in the family structure sample); household income (less than 25th percentile, 25-75th percentile, 75-100th percentile); educational attainment (HS/GED or less, some college but no Bachelor's, or a Bachelor's degree or higher); whether the mother has a coresident partner; whether the mother is White; age of youngest child $(0-1,2-4,5-7)$; number of household children under 8 (1, 2, or $3+)$; age $(18-31,32-37$, and 38+); and usual hours worked $(0,1-34$, or $35+)$. Because this calibration procedure sometimes assigns observations negative weights, we set all such negative weights equal to the lowest positive weight generated in the procedure.

Appendix Table B1 shows the average values of the covariates used in the regressions in Tables 3 and 4 in the full sample of mothers, in the unweighted assortative mating and specialization samples, and in the reweighted assortative mating and specialization samples. We see that the marginal distribution of the covariates in the full sample of mothers is virtually identical to that in the reweighted samples.

\section{References}

D'Souza, John. 2011. calibrate: Stata module to calibrate survey datasets to population totals. Statistical Software Components S457240, Boston College Department of Economics. (Online Link.)

Deming, W. Edwards and Frederick F. Stephan. 1940. "On a Least Squares Adjustment of a Sampled Frequency Table When the Expected Marginal Totals are Known." The Annals of Mathematical Statistics. 4:427-444.

Winter, Nicholas. 2002. survwgt: Stata module to create and manipulate survey weights. Statistical Software Components S427503, Boston College Department of Economics. (Online Link.) 


\section{Appendix Table B1: Mean Values of Regression Variables for Maternal Respondents}

\begin{tabular}{|c|c|c|c|c|c|}
\hline \multirow[b]{2}{*}{ Variable } & \multirow{2}{*}{$\begin{array}{c}\text { Full Family } \\
\text { Structure Sample }\end{array}$} & \multicolumn{2}{|c|}{ Assortative Mating Sample } & \multicolumn{2}{|c|}{ Specialization Sample } \\
\hline & & Unweighted & Weighted & Unweighted & Weighted \\
\hline Total Developmental Childcare Time & 82.6 & 79.0 & 82.6 & 74.8 & 82.6 \\
\hline$\% \mathrm{HS} / \mathrm{GED}$ or less & $39.0 \%$ & $39.4 \%$ & $39.0 \%$ & $39.2 \%$ & $39.0 \%$ \\
\hline$\%$ Some college, no BA & $26.2 \%$ & $25.2 \%$ & $26.2 \%$ & $24.6 \%$ & $26.2 \%$ \\
\hline$\% \mathrm{BA}$ or higher & $34.8 \%$ & $35.4 \%$ & $34.8 \%$ & $36.2 \%$ & $34.8 \%$ \\
\hline$\% 0-25$ th income pctile & $28.0 \%$ & $27.3 \%$ & $28.0 \%$ & $28.5 \%$ & $28.0 \%$ \\
\hline$\%$ 25-75th income pctile & $47.5 \%$ & $48.5 \%$ & $47.5 \%$ & $46.8 \%$ & $47.5 \%$ \\
\hline$\% 75$ th + income pctile & $24.5 \%$ & $24.2 \%$ & $24.5 \%$ & $24.7 \%$ & $24.5 \%$ \\
\hline$\%$ living with partner & $77.9 \%$ & $75.3 \%$ & $77.9 \%$ & $65.5 \%$ & $77.9 \%$ \\
\hline$\%$ White & $79.5 \%$ & $82.0 \%$ & $79.5 \%$ & $82.3 \%$ & $79.5 \%$ \\
\hline$\%$ youngest child $0-1$ & $39.0 \%$ & $38.7 \%$ & $39.0 \%$ & $37.6 \%$ & $39.0 \%$ \\
\hline$\%$ youngest child $2-3$ & $28.4 \%$ & $28.0 \%$ & $28.4 \%$ & $27.3 \%$ & $28.4 \%$ \\
\hline$\%$ youngest child $4-6$ & $32.6 \%$ & $33.3 \%$ & $32.6 \%$ & $35.0 \%$ & $32.6 \%$ \\
\hline$\%$ with 1 child aged $0-7$ & $63.6 \%$ & $65.3 \%$ & $63.6 \%$ & $67.8 \%$ & $63.6 \%$ \\
\hline$\%$ with 2 children aged $0-7$ & $29.9 \%$ & $29.2 \%$ & $29.9 \%$ & $27.6 \%$ & $29.9 \%$ \\
\hline$\%$ with $3+$ children aged $0-7$ & $6.5 \%$ & $5.5 \%$ & $6.5 \%$ & $4.6 \%$ & $6.5 \%$ \\
\hline$\%$ maternal age under 31 & $48.9 \%$ & $49.2 \%$ & $48.9 \%$ & $50.3 \%$ & $48.9 \%$ \\
\hline$\%$ maternal age $32-37$ & $25.6 \%$ & $25.3 \%$ & $25.6 \%$ & $24.4 \%$ & $25.6 \%$ \\
\hline$\%$ maternal age over 38 & $25.6 \%$ & $25.4 \%$ & $25.6 \%$ & $25.3 \%$ & $25.6 \%$ \\
\hline$\% 0$ maternal usual hours worked & $39.7 \%$ & $39.3 \%$ & $39.7 \%$ & $38.5 \%$ & $39.7 \%$ \\
\hline$\%$ 1-34 maternal usual hours worked & $17.7 \%$ & $17.8 \%$ & $17.7 \%$ & $16.0 \%$ & $17.7 \%$ \\
\hline$\% 35+$ maternal usual hours worked & $42.6 \%$ & $42.9 \%$ & $42.6 \%$ & $45.5 \%$ & $42.6 \%$ \\
\hline $\mathrm{N}$ & 16716 & 15023 & 15023 & 11131 & 11131 \\
\hline
\end{tabular}




\section{Appendix C: Accounting for Random Selection of Otherwise-Similar Synthetic Alters}

As described in our "Matching Procedure" section, for the purposes of estimating total parental developmental childcare time, we match ATUS respondents to other ATUS respondents ('alters') in two steps. First, we require an exact match on the coarsened values of variables used in the matching procedure; second, among potential alters who have an exact match on the coarsened variables, we select the alter who has the lowest Mahalanobis distance to the respondent based on the uncoarsened values of the matching variables.

Many respondents will have multiple alters who share the lowest Mahalanobis distance to the respondent, particularly when fewer matching variables are used (as is the case when matching on family structure). Randomly choosing one such alter as a match introduces randomness into our estimates of total parental childcare time for these respondents. When we estimate regression models predicting class gaps in total parental childcare time, then, this randomness introduces measurement error into the dependent variable. Measurement error in the dependent variable that is uncorrelated with independent variables does not increase the bias of our estimates of the regression parameters, but it does increase the variance of these estimates.

To account for this increased variance, we treat the estimating of total parental childcare time as a missing data problem, which can be handled using multiple imputation (see Rubin 1987). For each measure of total parental childcare time, we create 100 matches for each respondent, randomly choosing from all potential alters who have exact matches on the coarsened values of all variables used in the matching procedure and who have the lowest Mahalanobis distance to the respondent based on the uncoarsened values of matching variables. Respondents who only have one such match are matched with that respondent for all 100 matches.

We first use these 100 matches to create 100 different estimates of total parental childcare time for each respondent, $C_{i, 1}^{T}, \ldots, C_{i, 100}^{T}$. Then, we use these 100 different estimates of total parental childcare time in predicting class gaps in total parental childcare time, using the regression specified in Equation 2, leaving us with with 100 point estimates (and standard errors of the point estimates) of each regression coefficient. Finally, for each regression coefficient, we aggregate these 100 point estimates to create our multiple imputation point estimates and standard errors, which we report in our results. Let $\beta_{i, 1}, \ldots, \beta_{i, 100}$ be the 100 point estimates of the regression coefficient for variable $i$, and $S E \beta_{i, 1}, \ldots, S E \beta_{i, 100}$ be the standard errors of the above point estimates. Then, the multiple imputation estimate for the regression coefficient of variable $i, \hat{\beta}_{i}$ is simply the mean of the 100 point estimates:

$$
\hat{\beta}_{i}=\frac{\sum_{j=1}^{100} \beta_{i, j}}{100} .
$$

The standard error of the multiple imputation estimate for the regression coefficient of variable $i, S E \hat{\beta}_{i}$ is a function of standard errors of each of the 100 point estimates (the 'within-imputation' variance), as well as the variance of the point estimates across imputations (the 'between-imputation' variance):

$$
\left(S E \hat{\beta}_{i}\right)^{2}=\frac{\sum_{j=1}^{100}\left(S E \beta_{i, j}\right)^{2}}{100}+\frac{100+1}{100} \frac{\sum_{j=1}^{100}\left(\beta_{i, j}-\hat{\beta}_{i}\right)^{2}}{100-1} .
$$

\section{References}

Rubin, Donald B. 1987. Multiple Imputation for Nonresponse in Surveys. John Wiley \& Sons, Inc. 


\section{Appendix D: Estimating Total Developmental Childcare Time, Ad- justed for Parental Copresence}

Our main measure of total parental developmental childcare time sums up developmental childcare time of a respondent and their matched alter, and does not adjust for developmental childcare time that partners may perform together. However, we additionally report results using a measure of total developmental childcare time that accounts for childcare performed in the presence of one's partner, which we are able to calculate using filters on the ATUS-X website. Let

$$
C^{r}=C^{r, p}+C^{r, u}
$$

where $C^{r, p}$ represents developmental childcare time where one's partner is present and $C^{r, u}$ represents developmental childcare time where one's partner is not present. $C^{p, p}$ and $C^{p, u}$ are defined analogously. Then we define our adjusted measure of total developmental childcare time as:

$$
C^{T \prime}=C^{r, u}+C^{p, u}+\frac{C^{r, p}+C^{p, p}}{2} .
$$

That is, our adjusted measure is the sum of developmental childcare performed by the respondent and their alter that is not performed in the presence of either individual's partner, and half of developmental childcare performed by the respondent and their alter that is performed in the presence of either individual's partner. This adjusted measure makes the strong assumption that a partner is performing developmental childcare during the entire time when a respondent is performing developmental childcare and their partner is present. Because we can only know from the ATUS that a partner is present during a given activity and not what activity they are performing themselves, this measure is likely to underestimate total childcare time from the perspective of children. Since the original unadjusted measure is likely to overestimate total childcare time from the perspective of children, the use of both measures therefore helps bound estimates of total parental childcare time received by children.

We are unable to adjust these measures of total developmental childcare for time single parents spend in the presence of non-coresident co-parents, and vice versa, due to data limitations. Therefore, our estimates of joint developmental childcare time received by the children of single parents are likely to be overestimates, though we do expect that the amount of time single parents spend in childcare in the presence of non-coresident co-parents is likely to be small. 


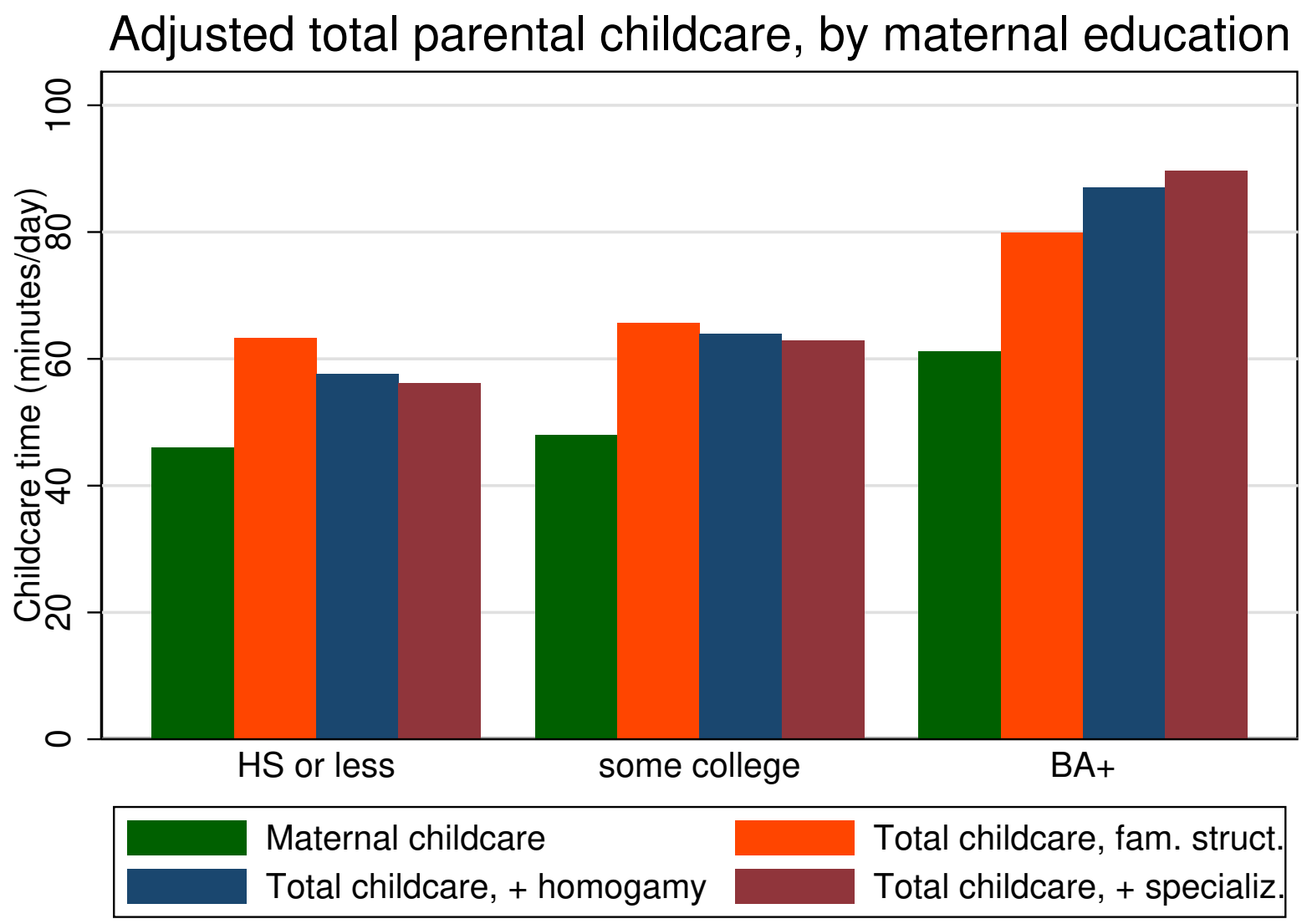


Appendix Figure D2: Comparison of Family Income-Gaps in Adjusted Developmental Childcare Time, by Matching Procedure

Adjusted total parental childcare, by household income

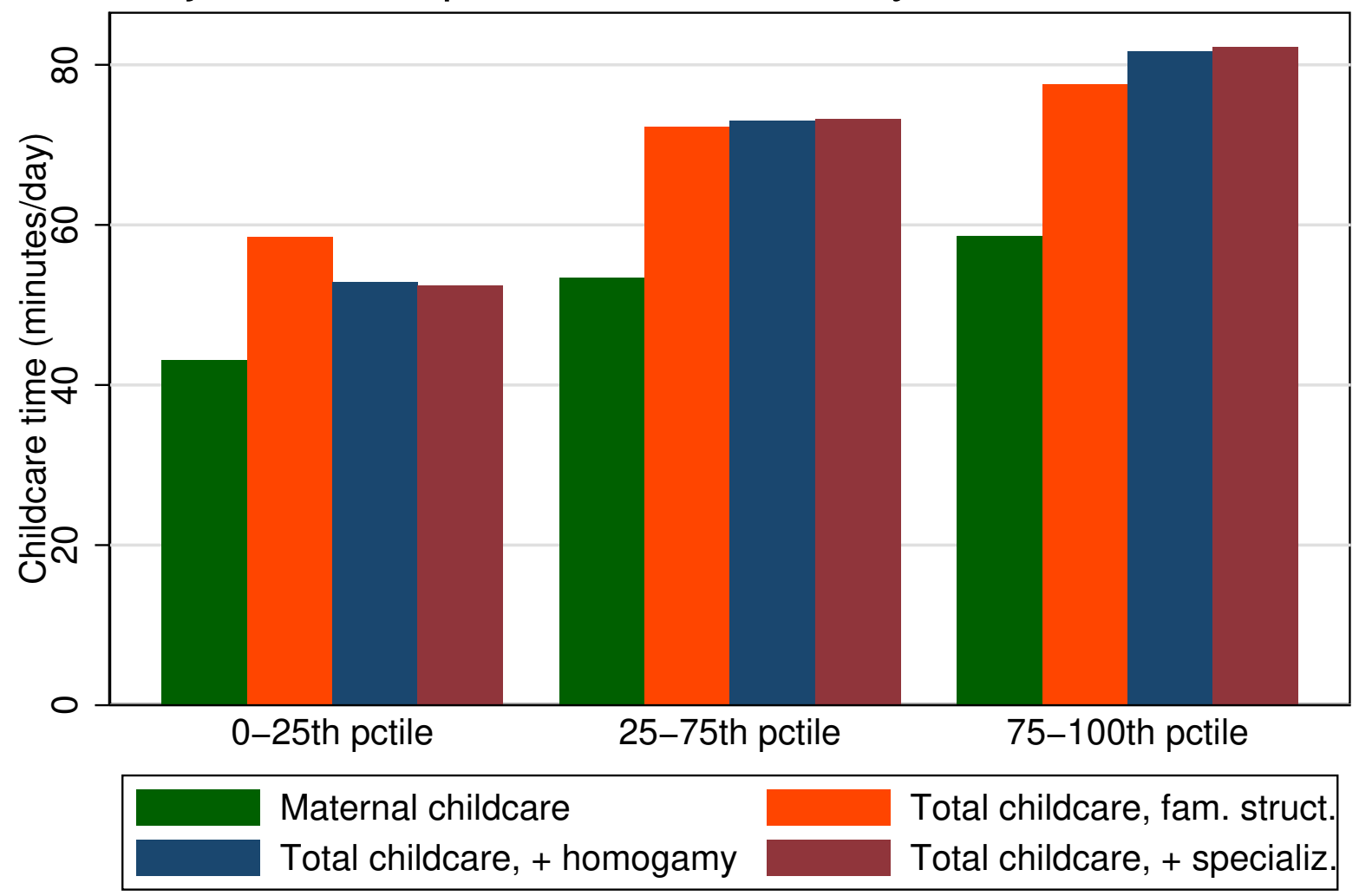




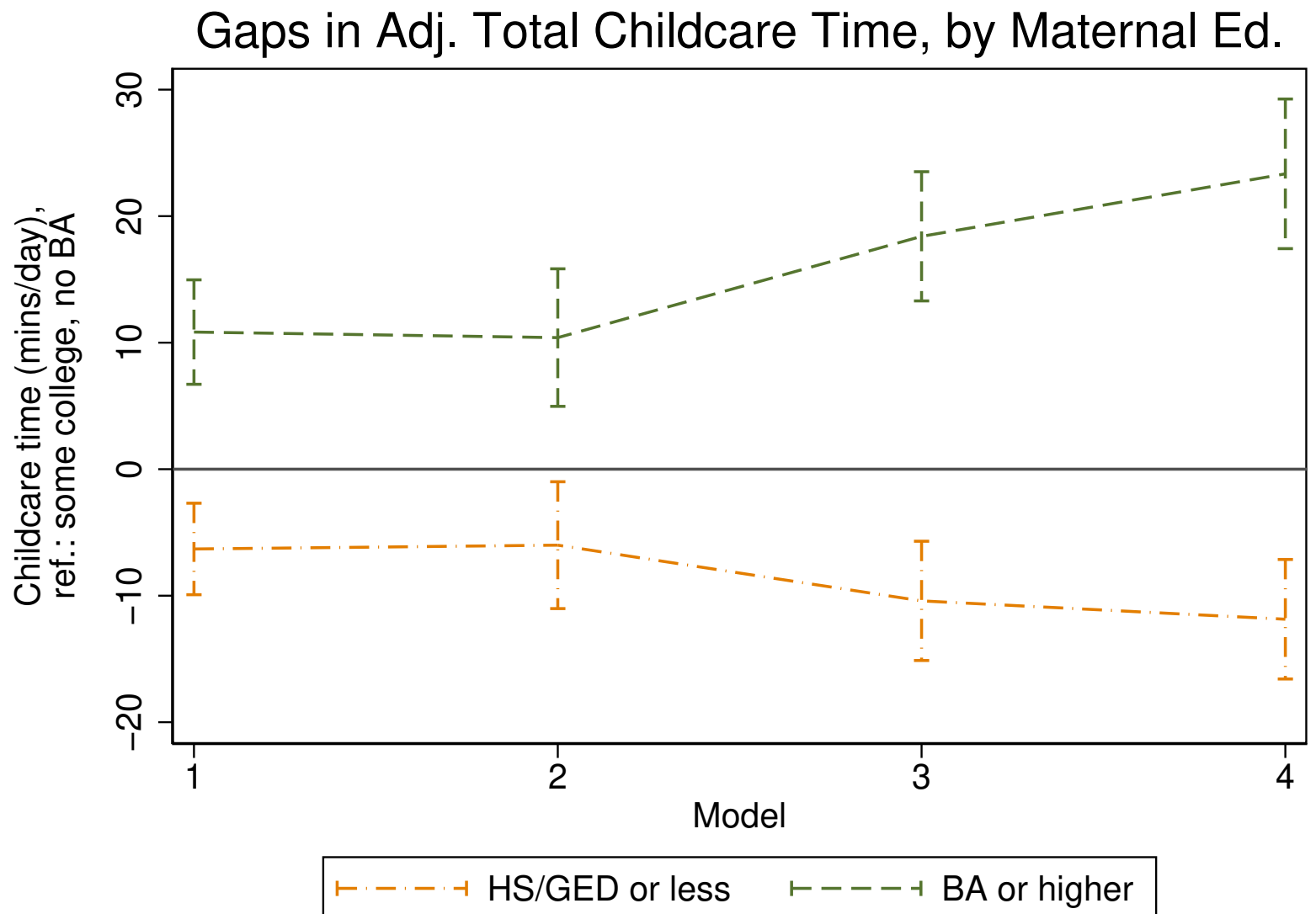

Note: The dependent variables in Models 1-4 are: 1) maternal childcare time, 2) total parental childcare time after accounting for family structure, 3) total parental childcare time after accounting for family structure and assortative mating, and 4) total parental childcare time after accounting for family structure, assortative mating, and specialization between partners. 


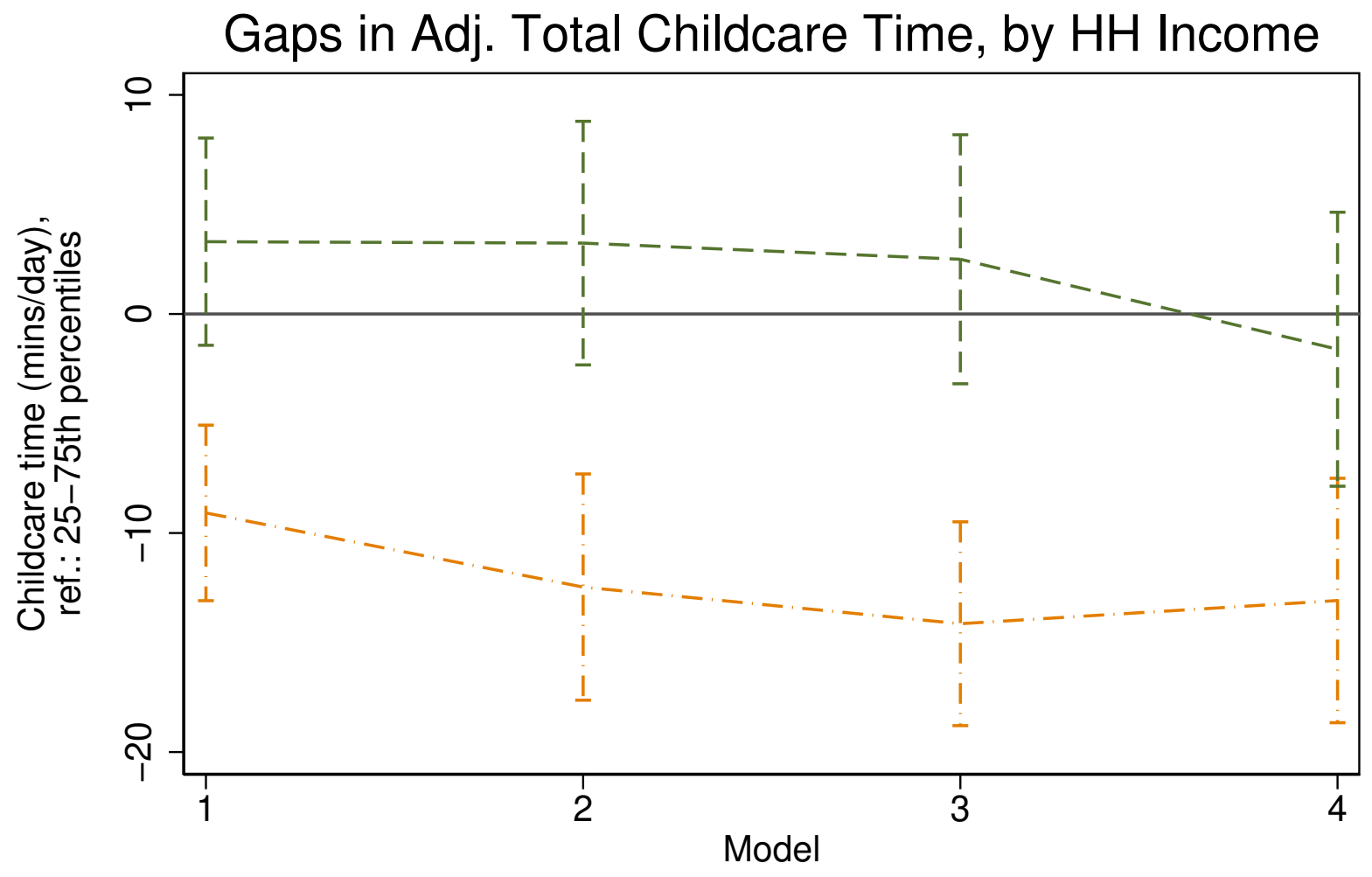

$\vdash--\dashv 0-25$ th percentiles $\vdash---\dashv 75$ th-100th percentiles

Note: The dependent variables in Models 1-4 are: 1) maternal childcare time, 2) total parental childcare time after accounting for family structure, 3) total parental childcare time after accounting for family structure and assortative mating, and 4) total parental childcare time after accounting for family structure, assortative mating, and specialization between partners. 
Appendix Table D1: Full Regression Results, Adjusted Measures of Total Parental Time

\begin{tabular}{|c|c|c|c|c|}
\hline & (1) & (2) & (3) & (4) \\
\hline HS/GED or less & $\begin{array}{c}-6.31^{* * *} \\
(1.85)\end{array}$ & $\begin{array}{l}-6.01^{*} \\
(2.56)\end{array}$ & $\begin{array}{c}-10.41^{* * *} \\
(2.40)\end{array}$ & $\begin{array}{c}-11.86^{* * *} \\
(2.41)\end{array}$ \\
\hline Some college, no BA & ref. & ref. & ref. & ref. \\
\hline BA or higher & $\begin{array}{c}10.84^{* * *} \\
(2.11)\end{array}$ & $\begin{array}{c}10.40^{* * *} \\
(2.77)\end{array}$ & $\begin{array}{c}18.41^{* * *} \\
(2.60)\end{array}$ & $\begin{array}{c}23.35^{* * *} \\
(3.02)\end{array}$ \\
\hline $0-25$ th pctile & $\begin{array}{c}-9.08^{* * *} \\
(2.04)\end{array}$ & $\begin{array}{c}-12.47^{* * *} \\
(2.63)\end{array}$ & $\begin{array}{c}-14.14^{* * *} \\
(2.37)\end{array}$ & $\begin{array}{c}-13.08^{* * *} \\
(2.85)\end{array}$ \\
\hline 25-75th pctile & ref. & ref. & ref. & ref. \\
\hline 75-100th pctile & $\begin{array}{c}3.30 \\
(2.41)\end{array}$ & $\begin{array}{c}3.23 \\
(2.84)\end{array}$ & $\begin{array}{c}2.50 \\
(2.90)\end{array}$ & $\begin{array}{l}-1.61 \\
(3.19)\end{array}$ \\
\hline \# HH children aged $0-7$ & $\begin{array}{c}1.44 \\
(1.40)\end{array}$ & $\begin{array}{l}4.95^{* *} \\
(1.85)\end{array}$ & $\begin{array}{c}5.25^{* * *} \\
(1.73)\end{array}$ & $\begin{array}{c}1.91 \\
(1.99)\end{array}$ \\
\hline Youngest child age & $\begin{array}{c}-5.55^{* * *} \\
(0.39)\end{array}$ & $\begin{array}{c}-6.61^{* * *} \\
(0.55)\end{array}$ & $\begin{array}{c}-7.33^{* * *} \\
(0.50)\end{array}$ & $\begin{array}{c}-7.03^{* * *} \\
(0.54)\end{array}$ \\
\hline Maternal age & $\begin{array}{c}0.11 \\
(0.15)\end{array}$ & $\begin{array}{c}0.26 \\
(0.19)\end{array}$ & $\begin{array}{c}0.25 \\
(0.18)\end{array}$ & $\begin{array}{c}0.28 \\
(0.18)\end{array}$ \\
\hline Mother is White & $\begin{array}{c}12.97^{* * *} \\
(1.84)\end{array}$ & $\begin{array}{c}14.70^{* * *} \\
(2.47)\end{array}$ & $\begin{array}{c}17.56^{* * *} \\
(2.09)\end{array}$ & $\begin{array}{c}16.80^{* * *} \\
(2.37)\end{array}$ \\
\hline Mother is employed & $\begin{array}{c}-30.70^{* * *} \\
(1.75)\end{array}$ & $\begin{array}{c}-30.65^{* * *} \\
(2.27)\end{array}$ & $\begin{array}{c}-31.97^{* * *} \\
(2.15)\end{array}$ & $\begin{array}{c}-28.36^{* * *} \\
(2.35)\end{array}$ \\
\hline Weekend diary & $\begin{array}{c}-2.80^{* *} \\
(1.34)\end{array}$ & $\begin{array}{l}-0.64 \\
(1.87)\end{array}$ & $\begin{array}{l}-1.09 \\
(1.52)\end{array}$ & $\begin{array}{c}1.18 \\
(1.87)\end{array}$ \\
\hline Observations & 16716 & 16716 & 15023 & 11131 \\
\hline
\end{tabular}




\section{Appendix Table D2: Comparison of Regression Coefficients Between Models in Appendix Table D1}

\begin{tabular}{|c|c|c|c|c|}
\hline Model Comparison & $\begin{array}{l}\text { Model } 2 \text { - } \\
\text { Model } 1\end{array}$ & $\begin{array}{l}\text { Model } 3 \text { - } \\
\text { Model } 2\end{array}$ & $\begin{array}{c}\text { Model } 4 \text { - } \\
\text { Model } 3\end{array}$ & $\begin{array}{l}\text { Model } 4 \text { - } \\
\text { Model } 1\end{array}$ \\
\hline HS/GED or less & $\begin{array}{c}0.30 \\
(0.10)\end{array}$ & $\begin{array}{l}-4.40 \\
(-1.25)\end{array}$ & $\begin{array}{l}-1.45 \\
(-0.43)\end{array}$ & $\begin{array}{ll}-5.55^{+} \\
\\
(-1.83)\end{array}$ \\
\hline Some college, no BA & ref. & ref. & ref. & ref. \\
\hline BA or higher & $\begin{array}{c}-0.44 \\
(-0.13)\end{array}$ & $\begin{array}{l}8.00^{*} \\
(2.10)\end{array}$ & $\begin{array}{l}4.94^{*} \\
(1.24)\end{array}$ & $\begin{array}{c}12.51^{* * *} \\
(3.40)\end{array}$ \\
\hline $0-25$ th pctile & $\begin{array}{l}-3.39 \\
(-1.02)\end{array}$ & $\begin{array}{l}-1.67 \\
(-0.47)\end{array}$ & $\begin{array}{l}1.06 \\
(0.29)\end{array}$ & $\begin{array}{ll} & -4.00 \\
& (-1.14)\end{array}$ \\
\hline 25-75th pctile & ref. & ref. & ref. & ref. \\
\hline 75-100th pctile & $\begin{array}{c}-0.24 \\
(-0.08)\end{array}$ & $\begin{array}{c}-0.74 \\
(-0.18)\end{array}$ & $\begin{array}{l}-4.11 \\
(-0.95)\end{array}$ & $\begin{array}{ll}-4.91 \\
& (-1.23)\end{array}$ \\
\hline \# HH children aged $0-7$ & $\begin{array}{c}3.51 \\
(1.51)\end{array}$ & $\begin{array}{c}0.30 \\
(0.12)\end{array}$ & $\begin{array}{l}-3.35 \\
(-1.27)\end{array}$ & $\begin{array}{c}0.46 \\
(0.19)\end{array}$ \\
\hline Youngest child age & $\begin{array}{l}-1.05 \\
(-1.57)\end{array}$ & $\begin{array}{c}-0.72 \\
(-0.97)\end{array}$ & $\begin{array}{c}0.30 \\
(0.41)\end{array}$ & $\begin{array}{ll} & -1.47^{*} \\
& (-2.22)\end{array}$ \\
\hline Maternal age & $\begin{array}{c}0.15 \\
(0.62)\end{array}$ & $\begin{array}{c}-0.01 \\
(-0.04)\end{array}$ & $\begin{array}{c}0.03 \\
(0.12)\end{array}$ & $\begin{array}{c}0.17 \\
(0.72)\end{array}$ \\
\hline Mother is White & $\begin{array}{c}1.73 \\
(0.56)\end{array}$ & $\begin{array}{c}2.86 \\
(0.88)\end{array}$ & $\begin{array}{l}-0.76 \\
(-0.24)\end{array}$ & $\begin{array}{c}3.83 \\
(1.28)\end{array}$ \\
\hline Mother is employed & $\begin{array}{c}0.05 \\
(0.02)\end{array}$ & $\begin{array}{c}-1.32 \\
(-0.42)\end{array}$ & $\begin{array}{c}3.61 \\
(1.13)\end{array}$ & $\begin{array}{c}2.34 \\
(0.80)\end{array}$ \\
\hline Weekend diary & $\begin{array}{c}2.16 \\
(0.94)\end{array}$ & $\begin{array}{l}-0.45 \\
(-0.19)\end{array}$ & $\begin{array}{c}2.26 \\
(0.94)\end{array}$ & $\begin{array}{l}3.98^{+} \\
(1.73)\end{array}$ \\
\hline
\end{tabular}

Note: The dependent variables in Models 1-4 are: 1) maternal childcare time, 2) total parental childcare time after accounting for family structure, 3) total parental childcare time after accounting for family structure and assortative mating, and 4) total parental childcare time after accounting for family structure, assortative mating, and specialization between partners. 